Full length article

\title{
3D bioprinting of prevascularised implants for the repair of critically-sized bone defects
}

\author{
Jessica Nulty ${ }^{\mathrm{a}, \mathrm{b}}$, Fiona E. Freeman ${ }^{\mathrm{a}, \mathrm{b}}$, David C. Browe ${ }^{\mathrm{a}, \mathrm{b}, \mathrm{d}}$, Ross Burdis ${ }^{\mathrm{a}, \mathrm{b}}$, Daniel P. Ahern ${ }^{\mathrm{a}, \mathrm{e}}$, \\ Pierluca Pitacco ${ }^{\mathrm{a}, \mathrm{b}}$, Yu Bin Lee ${ }^{\mathrm{f}}$, Eben Alsberg ${ }^{\mathrm{f}, \mathrm{g}}$, Daniel J. Kelly ${ }^{\mathrm{a}, \mathrm{b}, \mathrm{c}, \mathrm{d}, *}$ \\ a Trinity Centre for Biomedical Engineering, Trinity Biomedical Sciences Institute, Trinity College Dublin, Dublin, Ireland \\ ${ }^{\mathrm{b}}$ Department of Mechanical, Manufacturing and Biomedical Engineering, School of Engineering, Trinity College Dublin, Dublin, Ireland \\ ${ }^{\mathrm{C}}$ Department of Anatomy, Royal College of Surgeons in Ireland, Dublin, Ireland \\ ${ }^{\mathrm{d}}$ Advanced Materials and Bioengineering Research Centre (AMBER), Royal College of Surgeons in Ireland and Trinity College Dublin, Dublin, Ireland \\ e School of Medicine, Trinity College Dublin, The University of Dublin, Ireland \\ ${ }^{\mathrm{f}}$ Department of Biomedical Engineering, University of Illinois, Chicago, IL, USA \\ ${ }^{g}$ Departments of Orthopaedics, Pharmacology, and Mechanical E' Industrial Engineering, University of Illinois, Chicago, IL, USA
}

\section{A R T I C L E I N F O}

\section{Article history:}

Received 11 September 2020

Revised 6 February 2021

Accepted 3 March 2021

Available online 8 March 2021

\section{Keywords:}

3D bioprinting

Prevascularisation

Bone tissue engineering

Bioink

Rat femoral defect

\begin{abstract}
A B S T R A C T
For 3D bioprinted tissues to be scaled-up to clinically relevant sizes, effective prevascularisation strategies are required to provide the necessary nutrients for normal metabolism and to remove associated waste by-products. The aim of this study was to develop a bioprinting strategy to engineer prevascularised tissues in vitro and to investigate the capacity of such constructs to enhance the vascularisation and regeneration of large bone defects in vivo. From a screen of different bioinks, a fibrin-based hydrogel was found to best support human umbilical vein endothelial cell (HUVEC) sprouting and the establishment of a microvessel network. When this bioink was combined with HUVECs and supporting human bone marrow stem/stromal cells (hBMSCs), these microvessel networks persisted in vitro. Furthermore, only bioprinted tissues containing both HUVECs and hBMSCs, that were first allowed to mature in vitro, supported robust blood vessel development in vivo. To assess the therapeutic utility of this bioprinting strategy, these bioinks were used to prevascularise 3D printed polycaprolactone (PCL) scaffolds, which were subsequently implanted into critically-sized femoral bone defects in rats. Microcomputed tomography $(\mu \mathrm{CT})$ angiography revealed increased levels of vascularisation in vivo, which correlated with higher levels of new bone formation. Such prevascularised constructs could be used to enhance the vascularisation of a range of large tissue defects, forming the basis of multiple new bioprinted therapeutics.
\end{abstract}

\section{Statement of significance}

This paper demonstrates a versatile 3D bioprinting technique to improve the vascularisation of tissue engineered constructs and further demonstrates how this method can be incorporated into a bone tissue engineering strategy to improve vascularisation in a rat femoral defect model.

(C) 2021 Acta Materialia Inc. Published by Elsevier Ltd.

This is an open access article under the CC BY license (http://creativecommons.org/licenses/by/4.0/)
Abbreviations: VEGF, Vascular endothelial growth factor; FGF, Fibroblast growth factor; HUVECs, Human umbilical vein endothelial cells; hBMSCs, Human bone marrow-derived mesenchymal stem cells; nHA, Nano-hydroxyapatite; GelMA, Gelatin Methacryloyl.

* Corresponding author.

E-mail address: kellyd9@tcd.ie (D.J. Kelly).

\section{Introduction}

Tissue engineering is a multidisciplinary field which combines the principles of cell biology, materials science, and engineering to promote the regeneration of functional living tissues and organs. Although significant progress has been made in the field, for tissue engineering to become a clinically viable treatment option for the regeneration of tissues and organs in humans, vas- 
cularised scaled-up constructs are required. 3D bioprinting has emerged in recent years as a powerful tool that may enable the biofabrication of large, anatomically accurate tissues for regenerative medicine applications. 3D bioprinting is an additive manufacturing technique which involves the sequential, typically layerby-layer, deposition of biocompatible materials and cells to create a 3D construct [1]. When a printable biomaterial contains a biologic (a cell, nucleic acid or biomolecule) it is commonly referred to as a bioink [2]. Although 3D bioprinting theoretically enables the creation of cell-laden constructs of any size and shape, maintaining the viability and function of embedded cells both in vitro (during maturation of the engineered tissue) and in vivo (following its implantation into the body) remains a central challenge in the field.

Large, complex tissues require a circulatory system to provide all the nutrients and metabolites necessary for healthy metabolism and to remove any waste by-products. There are two processes by which a vascular network develops in vivo: vasculogenesis and angiogenesis. Vasculogenesis is the de novo development of blood vessels from early endothelial cells known as pre-angioblasts. Once vasculogenesis establishes basic vessels, angiogenesis can take place forming new blood vessels from pre-existing vasculature via sprouting and intussusception. Vascularisation is a slow process, the average growth rate of a newly developing capillary is only $\sim 5 \mu \mathrm{m} / \mathrm{h}$ [3]. This has led tissue engineers to explore different methods to accelerate the process of vascularisation within implanted constructs. Growth factors such as vascular endothelial growth factor (VEGF) and basic fibroblast growth factor (FGF-2), or other biological cues, are commonly incorporated into implants to encourage the ingrowth of vessels from surrounding tissue [4-7]. Other approaches involve the incorporation of hollow channels within the construct to act as conduits to accelerate the ingrowth of host vasculature into the construct in vivo [8-10]. Although these methods show promise and can reduce vascularisation times, both processes rely on the growth of host vessels from the periphery into the constructs. This ingrowth of host vessels may be too slow for larger implants, leading to cell death and/or loss of function in the central region of engineered tissues.

An alternative approach to address this challenge is to prevascularise a scaffold or engineered tissue with a capillary-like network prior to implantation [11]. It has been shown that such engineered vascular networks can anastomose with the host vasculature upon implantation into the body [12-14], enabling rapid perfusion of the engineered tissue in vivo. Early studies into the assembly of microvascular networks in vitro focused on utilising such engineered tissues as model systems for studying angiogenesis, whereby capillary-like vessels are generated within soft 3D hydrogels such as fibrin [15-17], collagen [18,19] and fibronectin [20]. This opens up the possibility of using such hydrogels as bioinks to 3D bioprint prevascularised constructs, assuming they can be appropriately modified to be made compatible with modern biofabrication technologies used in the field of tissue engineering today.

The aim of this study was two-fold. We first sought to develop a 3D bioprinting strategy to generate prevascularised tissues of predefined size and shape in vitro, and to demonstrate the capacity of these constructs to support vascularisation in vivo (Fig. 1A). We then sought to assess the capacity of these 3D bioprinted, prevascularised tissues to elicit a therapeutic benefit following their implantation into a large bone defect (Fig. 1B). To this end, we first screened a range of different bioinks (gelatin methacrylamide, fibrin and alginate) for their print fidelity and capacity to support endothelial sprouting using human umbilical vein endothelial cells (HUVECs). We then explored specific cell combinations (co-cultures of HUVECs and hBMSCs) and in vitro culturing regimes, to enable the 3D bioprinting of prevascularised constructs. Finally, this versatile 3D bioprinting strategy was used to prevascularise nano-hydroxyapatite (nHA) functionalised PCL scaffolds, which were subsequently implanted into large bone defects in rats to assess their capacity to accelerate vascularisation and bone formation.

\section{Materials and methods}

\subsection{Bioink Fabrication}

Fibrin Bioink: To enable the use of fibrin as a printable bioink, a gelatin carrier method was adapted from Kang et al. [21]. Briefly, hyaluronic acid (Sigma) was added to Dulbecco's Modified Eagle Medium (DMEM; Gibco, Biosciences) at a concentration of $3 \mathrm{mg} / \mathrm{mL}$ and stirred overnight at $37{ }^{\circ} \mathrm{C} .10 \%(\mathrm{v} / \mathrm{v})$ glycerol (Sigma) was then added and the solution was stirred for $1 \mathrm{~h}$ at room temperature. Gelatin type A (175 g bloom; Sigma) was added at a concentration of $40 \mathrm{mg} / \mathrm{mL}$ and stirred for $2 \mathrm{~h}$ at $37{ }^{\circ} \mathrm{C}$ until fully dissolved. Before use fibrinogen (Sigma) was added to this carrier gel at a concentration of $30 \mathrm{mg} / \mathrm{mL}$ and stirred for $2 \mathrm{~h}$ at $37{ }^{\circ} \mathrm{C}$. To enhance the angiogenicity of the gel, D-erythro-sphingosine-1phosphate (Avanti Polar lipids, AL, USA) was added at a concentration of $125 \mu \mathrm{M} / \mathrm{mL}$ for all cell studies.

$\gamma$-irradiated RGD-modified Alginate Bioink: Briefly, low molecular weight sodium alginate $(\gamma$ alginate, $58000 \mathrm{~g} / \mathrm{mol})$ was prepared by irradiating sodium alginate (MVG, $259000 \mathrm{~g} / \mathrm{mol}$, Pronova Biopolymers, Oslo, Norway) at a gamma dose of $5 \mathrm{Mrad}$, as previously described [22]. RGD-modified alginates were prepared by coupling the GGGGRGDSP to the alginate using standard carbodiimide chemistry. Briefly, $10 \mathrm{~g}$ alginate was dissolved at $1 \%$ $(\mathrm{w} / \mathrm{v})$ in 2-(N-morpholino)ethanesulfonic acid (MES) Buffer $(0.1 \mathrm{M}$ MES, $0.3 \mathrm{M} \mathrm{NaCl}$, and pH 6.5). $274 \mathrm{mg}$ N-hydroxysulfosuccinimide (Pierce, Rockford, IL), $484 \mathrm{mg}$ ethylene dichloride (EDC; Sigma), and $100 \mathrm{mg}$ GGGGRGDSP peptide (AIBioTech, Richmond, VA) were then added to the alginate solution. The reaction was stopped and the solution was purified and lyophilised as previously described [23]. This lyophilised solution was prepared for use by combining with a gelatin carrier gel similar to that employed with the fibrinogen, described previously, with the substitution of gelatin type A (75 g bloom, Sigma). To enhance the angiogenicity of the gel, Derythro-sphingosine-1-phosphate (Avanti Polar lipids) was added at a concentration of $125 \mu \mathrm{M} / \mathrm{mL}$ during all cell studies.

Gelatin Methacrylate (GelMA) Bioink: GelMA was synthesised by reaction of porcine type A gelatin (Sigma; gel strength $\sim 175 \mathrm{~g}$ bloom) with methacrylic anhydride (Sigma Aldrich) at $50{ }^{\circ} \mathrm{C}$ for $4 \mathrm{~h}$. Methacrylic anhydride was added to a $10 \%$ solution of gelatin in PBS under constant stirring. To achieve a high degree of functionalisation, $0.6 \mathrm{~g}$ of methacrylic anhydride was added per gram of gelatin. The functionalised polymer was dialyzed against distilled water for 7 days at $40{ }^{\circ} \mathrm{C}$ to remove methacrylic acid and anhydride, lyophilised and stored at $-20{ }^{\circ} \mathrm{C}$ until use. This protocol has been shown to support a degree of methacrylation of approximately $75 \%[24,25]$ although no confirmation of the degree of methacrylation was undertaken. To enhance the angiogenicity of the gel, D-erythro-sphingosine-1-phosphate (Avanti Polar lipids) was added at a concentration of $125 \mu \mathrm{M} / \mathrm{mL}$ during all cell studies.

\subsection{D Bioprinting system}

Bioink scaffolds were produced using the 3D Discovery multihead bioprinting system (Regen Hu, Switzerland). The bioinks were printed using a pneumatic driven syringe with a 25 Gauge needle under pressures of between $0.05 \mathrm{MPa}$ and $0.2 \mathrm{MPa}$. Prior to printing the $\gamma$ - RGD alginate bioink was pre-crosslinked thor- 

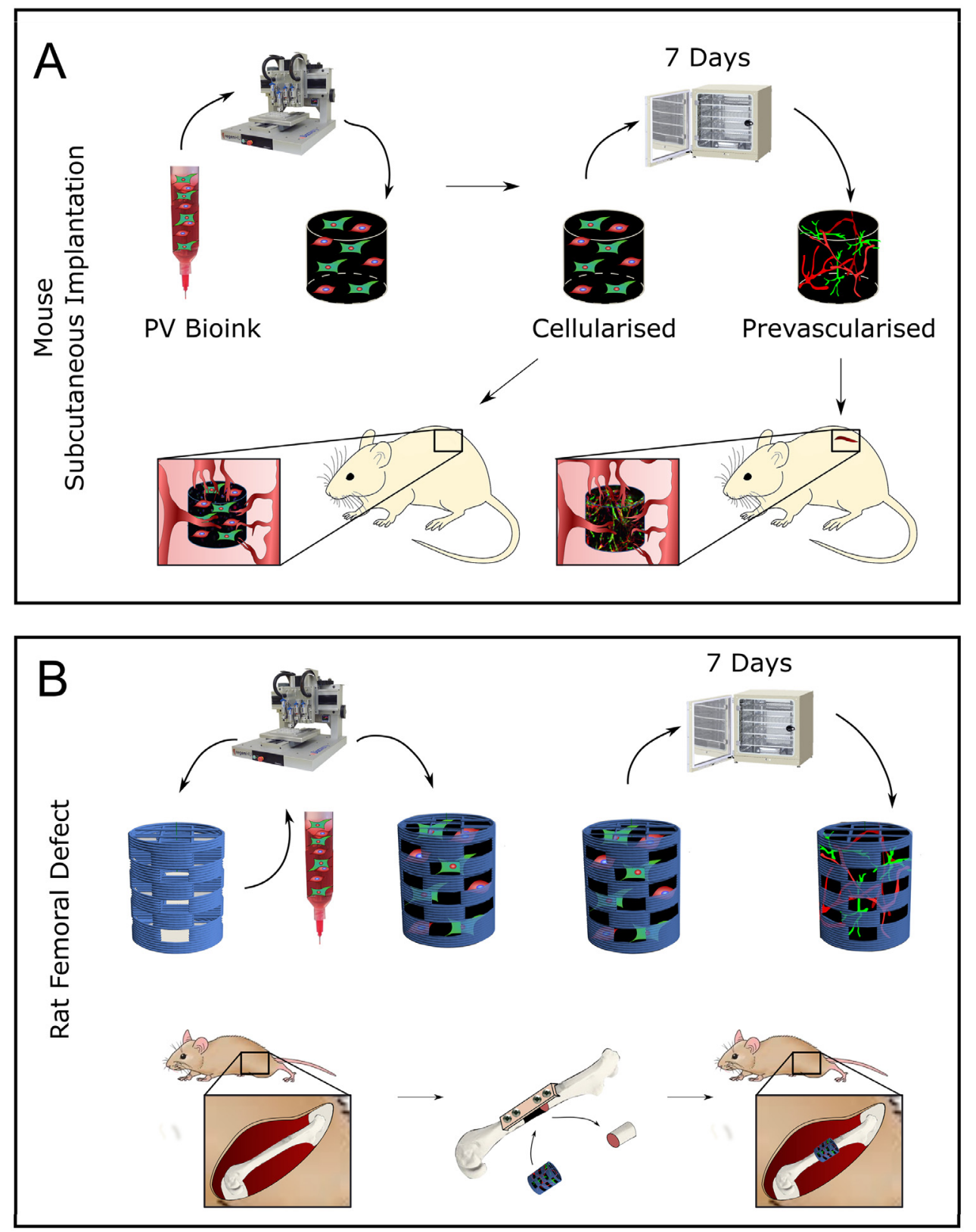

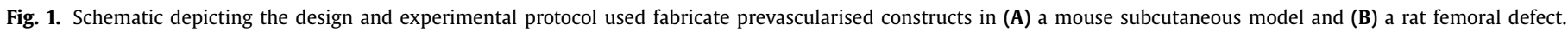

oughly with $60 \mathrm{mM} \mathrm{CaCl}$. A luer lock dual syringe system was used to thoroughly mix the alginate and calcium solutions in a 7:3 ratio as previously described [26]. To ensure homogeneity, the suspension was mixed between syringes 25 times. The solution (2.45 wt\% RGD- $\gamma$ alginate final) was then combined with HUVECs. Next the pre-crosslinked cell-laden alginate solution was loaded into the pressure driven piston system for printing. Post-printing, the constructs were immersed in a $100 \mathrm{mM} \mathrm{CaCl} 2$ solution for 15 min to fully crosslink the alginate bioink. Before printing, $10 \%$ (w/v). GelMA solution was mixed with Irgacure photoinitiator 2959 (2-Hydroxy-4'-(2-hydroxyethoxy)-2-methylpropiophenone; 0.05\%, Sigma) prior to loading with HUVECs, enabling post crosslinking after printing through the application of UV light (Uvitec, Cambridge UK) for $30 \mathrm{~min}\left(365 \times 10^{-9} \mathrm{~m}, 180 \mathrm{~mW} / \mathrm{cm}^{2}\right)$. Cells were added to this GelMA in a $1: 1$ ratio resulting in a final polymer concentration of $5 \%$ GelMA. No further modifications were made to the fibrin bioink prior to printing other than the addition of HUVECs. After printing, the construct was immersed in a thrombin (Sigma) bath $\left(20 \mathrm{U} / \mathrm{mL}^{1}\right)$ for $15 \mathrm{~min}$ at room temperature to al- low the thrombin-catalysed polymerization of fibrinogen to fibrin. The 3D Discovery bioprinter was encased in a laminar flow hood to ensure sterility throughout the biofabrication process. All three bioinks were loaded with HUVECs between P4 - P6 (10 million cells $/ \mathrm{mL}^{1}$ and 3 million cells $/ \mathrm{mL}$ for cell viability and sprouting studies respectively). In addition, fibrin bioinks were loaded with a co-culture of HUVECs and hBMSCs in a 1:1 ratio (3 million HUVECs/mL and 3 million hBMSCs/mL) and a 2:1 ratio (3 million HUVECs cells/mL and 1.5 million hBMSCs $/ \mathrm{mL}$ ) for stabilisation studies.

For constructs implanted subcutaneously into nude mice (further details below), bioinks were deposited into a cylindrical 3D printed polycaprolactone (PCL; CAPA Ingevity, SC, USA) sheath (wall thickness $=0.25 \mathrm{~mm}$; diameter $=4 \mathrm{~mm}$; height $=4 \mathrm{~mm}$ ). For constructs implanted into large bone defects in rats (further details below), bioinks were deposited into 3D printed PCL scaffolds ( $5 \mathrm{~mm}$ height, $4 \mathrm{~mm}$ diameter; see Fig. $4 \mathrm{~A}$ ). PCL was printed at $80{ }^{\circ} \mathrm{C}$ at $0.5 \mathrm{MPa}$ using a $27 \mathrm{G}$ needle. For these rat studies the PCL scaffolds were additionally coated with nano hydroxyapatite (nHA; further details of the coating procedure are provided below) 
and sterilised using ethylene oxide (EtO) gas prior to the addition of cell-laden bioinks.

\subsection{Cell Culture}

Human Umbilical Vein Endothelial cells (HUVECs; Lonza, Walkersville, MD) were used in this study. HUVECs are a primary cell line and were routinely used between passage 4 and passage 8 . HUVECs were cultured in Endothelial Growth Medium (EGM-2) which had been supplemented with EGM-2 BulletKit ${ }^{\circledR}$ (Lonza). HUVECs were typically grown in T-175 flasks (Fisher) with $20 \mathrm{~mL}$ of media per flask and incubated at $37{ }^{\circ} \mathrm{C}$ in a humidified atmosphere with $5 \% \mathrm{pCO}_{2}$. The media was changed every two days until cells were approximately 85\% confluent. Trypsin Ethylenediaminetetraacetic acid (EDTA) was used to remove adhered cells at $37{ }^{\circ} \mathrm{C}$ for $(3-5) \mathrm{min}$. The harvested cells were centrifuged at $350 \mathrm{x}$ $\mathrm{g}$ for $4 \mathrm{~min}$. For the sprouting studies, HUVECs were used between P4 - P6 (3 million cells $/ \mathrm{mL}^{1}$ ) and grown in EGM-2 supplemented with VEGF $(50 \mathrm{ng} / \mathrm{mL})$.

Human BMSCs (hBMSCs) were isolated from unprocessed human bone marrow (Lonza) on the basis of plastic adherence. Briefly, unprocessed bone marrow was plated at $2.5 \times 10^{5}$ cells $/ \mathrm{cm}^{2}$ (estimated approx. $4000-5000 \mathrm{hBMSCs} / \mathrm{cm}^{2}$ ) in high glucose Dulbecco's modified eagle's medium (hgDMEM) GlutaMAX supplemented with $10 \% \mathrm{v} / \mathrm{v}$ FBS, $100 \mathrm{U} / \mathrm{mL}$ penicillin, $100 \mu \mathrm{g} / \mathrm{mL}$ streptomycin (all Gibco, Biosciences, Dublin, Ireland) and $5 \mathrm{ng} / \mathrm{mL}$ FGF-2 (Prospect Bio) and expanded under hypoxic conditions $\left(37{ }^{\circ} \mathrm{C}\right.$ in a humidified atmosphere with $5 \% \mathrm{pCO}_{2}$ and $5 \% \mathrm{pO}_{2}$ ) for improved chondrogenic differentiation. Following colony formation, hBMSCs were trypsinised using $0.25 \%(\mathrm{w} / \mathrm{v})$ Trypsin Ethylenediaminetetraacetic acid (EDTA) and tripotentiality was confirmed as previously described [27]. hBMSCs used were seeded at 5000 cells $/ \mathrm{cm}^{2}$ expanded in DMEM supplemented with $10 \% \mathrm{v} / \mathrm{v}$ FBS, $100 \mathrm{U} / \mathrm{mL}$ penicillin, $100 \mu \mathrm{g} / \mathrm{mL}$ streptomycin (all Gibco, Biosciences, Dublin, Ireland) and $5 \mathrm{ng} / \mathrm{mL}$ FGF-2 (Prospect Bio) and expanded under normoxic conditions $\left(37{ }^{\circ} \mathrm{C}\right.$ in a humidified atmosphere with $5 \% \mathrm{pCO}_{2}$ and $20 \% \mathrm{pO}_{2}$ ) and used at $\mathrm{P} 4$.

\subsection{Live/dead cell assay}

Cell viability was established using a live/dead assay. Printed cell-laden constructs were incubated in EGM-2 media for 30 min prior to the assay. All constructs were rinsed in PBS and incubated for $1 \mathrm{~h}$ in a solution containing $2 \mu \mathrm{M}$ calcein and $4 \mu \mathrm{M}$ of ethidium homodimer-1 (Cambridge Biosciences). After incubation, the constructs were rinsed again, cut in half and imaged with Olympus FV-1000 Point-Scanning Confocal Microscope (488 nm and $543 \mathrm{~nm}$ channels). Cell viability was quantified using Image-J software.

\subsection{Confirmation of gelatin elimination}

To investigate whether or not the additional gelatin had been removed following incubation at $37^{\circ} \mathrm{C}$, a hydroxyproline biochemical analysis was carried out for both the fibrin- and alginate-based bioinks as previously described [28]. Gelatin was then quantified by its hydroxyproline content, after hydrolysis $\left(110^{\circ} \mathrm{C} ; 18 \mathrm{~h}\right)$ in $\mathrm{HCl}$ (38\%), and assayed using chloramine-T assay assuming 13\% hydroxyproline per gelatin molecule [29].

\subsection{Scanning electron microscopy (SEM)}

Samples were prepared for SEM by dehydrating samples in decreasing ethanol series and immersed in hexamethyldisilazane (HMDS; $2 \times 30 \mathrm{~min}$ ). Samples were allowed to air dry for $2 \mathrm{~h}$ before being mounted on SEM stubs and left overnight to ensure complete removal of solvent. Fibrin samples and PCL scaffolds were then coated with gold/palladium for $120 \mathrm{~s}$ and $60 \mathrm{~s}$ respectively at a current of $40 \mathrm{~mA}$ using a Cressington 208HR sputter coater. SEM imaging was conducted at $5 \mathrm{kV}$ in a Zeiss ULTRA plus.

\subsection{In vitro microvessel assessment}

For assessing microvessel establishment, all GelMA and fibrinbased samples were fixed in $4 \%$ paraformaldehyde overnight. Alginate samples were fixed in 4\% PFA supplemented with barium chloride overnight to permanently crosslink the gels. Samples were then washed in PBS, permeabilised in $0.5 \%$ Triton-X (Sigma) and incubated with Rhodamine Phalloidin $(5 \mathrm{U} / \mathrm{mL} ; 165 \mathrm{nM}$; Thermo Fisher) for $40 \mathrm{~min}$ at $37{ }^{\circ} \mathrm{C}$ followed by DAPI $\left(4^{\prime}, 6\right.$-diamidino-2phenylindole; $1 \mathrm{ug} / \mathrm{mL}$; Sigma) incubation for $20 \mathrm{~min}$ at room temperature. After incubation, the constructs were rinsed again, cut in half and imaged with Olympus FV-1000 Point-Scanning Confocal Microscope at $565 \mathrm{~nm}$ and $461 \mathrm{~nm}$ channels. Vessel lengths were calculated on projected stacks using either ImageJ or Angiotool [30] which is a program capable of detecting, marking and scoring the average vessel length.

\subsection{Subcutaneous implantation}

All animal experiments were performed in accordance with EU Directive 2010/63/EU on the protection of animals used for scientific purposes. Four groups were bioprinted: HUVECs alone (3 million cells $/ \mathrm{mL}$ ), hBMSCs alone (1.5 million cells $/ \mathrm{mL}$ ), a 2:1 ratio of HUVECs: hBMSCs (3 million:1.5 million $/ \mathrm{mL}$ ) and a cell-free control. These 4 groups were exposed to one of two conditions; either grown in EGM-2 (Lonza) supplemented with $50 \mathrm{ng}$ of recombinant human VEGF (Gibco) at $37{ }^{\circ} \mathrm{C}$ in a humidified atmosphere for 7 days or implanted into the mice without any further culturing or exposure to VEGF. Constructs were implanted subcutaneously into the back of BALB/cOlaHsd-Foxn $1^{\text {nu }}$ female nude mice (Envigo). Briefly, two subcutaneous pockets were made along the central line of the spine, one at the shoulders and the other at the hips. Three constructs were inserted into each pocket (randomised between top and bottom pockets). Nine constructs were implanted per group and constructs were harvested 7 days and 14 days post-implantation. Mice were anaesthetised using an intraperitoneal injection of xylazine hydrochloride and ketamine hydrochloride. Carprofen was added to water for $48 \mathrm{~h}$ post-surgery, and mice were sacrificed by $\mathrm{CO}_{2}$ inhalation. This protocol and study were approved by the animal welfare committee of Trinity College Dublin and the Health Products Regulatory Agency (HPRA, approval number AE19136/P069).

\subsection{Nano hydroxyapatite ( $\mathrm{nHA}$ ) coating of PCL scaffolds}

PCL scaffolds were coated according to a protocol previously published and extensively characterised [31]. To coat PCL scaffolds with nano hydroxyapatite (nHA) needles with a mean length of $100 \mathrm{~nm}$ and mean diameter of $37 \mathrm{~nm}$, scaffolds were washed in $70 \%$ ethanol for 15 min under vacuum. Scaffolds were then immersed in $2 \mathrm{M} \mathrm{NaOH}$ at $37{ }^{\circ} \mathrm{C}$ for $45 \mathrm{~min}$. Scaffolds were then washed in milliQ water before being immersed in $0.05 \mathrm{M}$ calcium solution (Sigma). Equal parts $0.03 \mathrm{M}$ phosphate solution was added dropwise, and scaffolds were incubated for $30 \mathrm{~min}$ at $37^{\circ} \mathrm{C}$. This process was repeated two more times resulting in a total of three coatings. Scaffolds were then immersed in $0.5 \mathrm{M} \mathrm{NaOH}$ and incubated for $30 \mathrm{~min}$ before being washed in milliQ water and left to dry.

\subsection{Rat femoral defect surgical procedure}

Male Wistar Han rats were bred in the Comparative Medicine Unit of the Trinity Biomedical Sciences Institute (TBSI). For the 
rat segmental surgery, 27 12-week old rats were anesthetised using $2 \%-4 \%(\mathrm{v} / \mathrm{v})$ isoflurane in balanced oxygen and administered pre-operative analgesia of buprenorphine $(0.5 \mathrm{mg} / \mathrm{kg})$. Surgical access to the femur was achieved via an anterolateral longitudinal skin incision and separation of the hind limb muscles, the vastus lateralis and biceps femoris. The femoral diaphysis was exposed by circumferential elevation of attached muscles and the periosteum removed. Before the creation of the defect, a weight-bearing polyether ether ketone (PEEK) internal fixation plate was secured to the anterolateral femur. Holes were created in the femur with a surgical drill using the plate as a template. Screws were then inserted into the drill holes in the femur to maintain the fixation plate in position. A $5 \mathrm{~mm}$ mid-diaphyseal defect was created using an oscillating surgical saw under constant irrigation with sterile saline solution. Scaffolds were press-fit into the defect. Soft tissue was accurately readapted with absorbable suture material. Closure of the skin wound was achieved using suture material and tissue glue. Animals received daily systemic administration of immunosuppressive drugs FK506 (3.33 mg/mL) and SEW2871 $(1.66 \mathrm{mg} / \mathrm{mL})$ for 3 weeks post-operation as previously described [32,33]. This animal procedure and study was approved by the ethics committee in Trinity College Dublin and the Health Products Regulatory Authority (HPRA) in Ireland (Approval - AE19136/P087). One defect was created per animal, $n=9$ for both groups at both timepoints. 18 rats received a prevascularised nHA coated PCL scaffold (PV scaffold) and 18 rats received a nHA coated PCL control scaffold (Scaffold only). Two weeks post-operation, $\mu \mathrm{CT}$ angiography was performed (see below). Live $\mu \mathrm{CT}$ analysis was performed on remaining rats at 6 - and 12 -weeks post-operation (see below). At 12 weeks rats were sacrificed by $\mathrm{CO}_{2}$ asphyxiation and the affected femur, with the PEEK plate fixator intact, was excised for further analysis. One rat from the Scaffold only group had to be excluded from analysis due to complications post-surgery.

\subsection{Vascular $\mu C T$ analysis}

Using Scanco Medical vivaCT 80 system (Scanco Medical, Bassersdorf, Switzerland), contrast enhanced angiography was performed at week 2 post-operative to assess vascularisation within the bone defects. First, the rat was sacrificed using $\mathrm{CO}_{2}$ asphyxiation. Next, the vasculature was immediately perfused through the ascending aorta with sequential solutions of heparin $(25 \mathrm{U} / \mathrm{ml})$, (10\%) formalin, PBS (All Sigma), and a radiopaque contrast agent Microfil (Flow Tech, Carver, MA, USA). Microfil was prepared freshly prior to each procedure using $28 \%(\mathrm{v} / \mathrm{v})$ pigmented compound $69 \%(\mathrm{v} / \mathrm{v})$ diluent $3 \%(\mathrm{v} / \mathrm{v})$ curing agent. All solutions were thoroughly mixed before perfusion and maintained at $37{ }^{\circ} \mathrm{C}$ for the duration of the perfusion procedure. A straight $20 \mathrm{G}$ intravenous catheter was used to deliver the perfusion solutions into the rat's left ventricle. The right atrium was cut, and a peristatic pump was used to deliver the heparin, formalin, and PBS solutions at a rate of $6 \mathrm{ml} / \mathrm{min}$. The contrast agent was delivered at a rate of $3 \mathrm{ml} / \mathrm{min}$. After perfusion, animals were left overnight at $4{ }^{\circ} \mathrm{C}$ to allow the Microfil to cure. The limbs were excised and scanned using $\mu \mathrm{CT}$ with both bone and contrast agent present. To facilitate visualisation and quantification of the vascular volume alone, the excised limbs were next decalcified in EDTA ( $15 \mathrm{w} / \mathrm{v} \%, \mathrm{pH}$ 7.4) for 2 weeks to remove the bone mineral content. $\mu \mathrm{CT}$ scans were performed after decalcification. By comparing the two scans (pre- and postdecalcification) it was possible to define the defect VOI by using the relative position of the fixation screws present in both scans. Next, 3D evaluations were carried out on the segmented images to determine vascular volume and to reconstruct a 3D image. The vascular volume in the defect was quantified by measuring the total quantity of mineral in the centre of the defect. The vessel thickness, degree of anisotropy, and connectivity were analysed using trabecular thickness analysis scripts provided by SCANCO. $n=6$ was selected from each group for quantification.

\subsection{Micro-computed tomography $(\mu C T)$}

Micro-computed tomography $(\mu \mathrm{CT})$ scans for vessel analysis were performed using a Scanco Medical $40 \mu \mathrm{CT}$ system (Scanco Medical, Bassersdorf, Switzerland). Samples were scanned at a voxel resolution of $10 \mu \mathrm{m}$, a voltage of $70 \mathrm{kVp}$, and a current of $113 \mu \mathrm{A}$. Reconstructed 3D images were generated using a Gaussian filter ( $\operatorname{sigma}=3$, support $=5$ ) was used to suppress noise site and a global threshold of 363 .

In vivo $\mu \mathrm{CT}$ scans were performed on constructs using a Scanco Medical vivaCT 80 system (Scanco Medical, Bassersdorf, Switzerland). Rats ( $n=9$ ) were scanned at 2 weeks before angiography was performed. All other rats $(n=9)$ received scans at 6 - and 8 -weeks post-surgery to assess bone formation within the defect. Animals were anesthetised using 2-4\% (v/v) isoflurane in balanced oxygen throughout the scan. Next, a radiographic scan of the whole animal was used to isolate the rat femur. The animal's femur was aligned parallel to the scanning field-of-view to simplify the bone volume assessments. Scans were performed using a voltage of 70 $\mathrm{kVp}$, and a current of $114 \mu \mathrm{A}$. A Gaussian filter (sigma $=0.8$, support $=1$ ) was used to suppress noise and a global threshold of 210 , corresponding to a density of $399.5 \mathrm{mg}$ hydroxyapatite $/ \mathrm{cm}^{3}$ was applied. A voxel resolution of $35 \mu \mathrm{m}$ was used throughout. 3D evaluation was carried out on the segmented images to determine bone volume and density and to reconstruct a 3D image. Bone volume and bone density in the defects was quantified by measuring the total quantity of mineral in the central $5 \mathrm{~mm}$ of the defect.

\subsection{Colony-forming unit (CFU) analysis of individual rat bone marrow}

To assess differences in the number of colony-forming units (CFUs) present in the bone marrow of individual rats, the contralateral femurs were excised. Under sterile conditions, the bone ends were cut and the bone marrow was flushed out using an 18 Gauge needle and hgDMEM GlutaMAX supplemented with 10\% v/v FBS, $100 \mathrm{U} / \mathrm{mL}$ penicillin, $100 \mu \mathrm{g} / \mathrm{mL}$ streptomycin (all Gibco, Biosciences, Dublin, Ireland) into a $50 \mathrm{~mL}$ falcon tube. The volume was made up to $20 \mathrm{~mL}$ with media and triturated to remove any marrow clumps. Samples were then centrifuged at $650 \mathrm{x}$ g for $5 \mathrm{~min}$. The supernatant was discarded, and the pellet was transferred to a fresh falcon tube. More media was added, the pellet was triturated, and the sample centrifuged again at $650 \mathrm{x}$ g for $5 \mathrm{~min}$. Once again, the supernatant was discarded. The pellet was resuspended and passed through a $40 \mu \mathrm{m}$ nylon mesh. A cell count was performed using 3\% (v/v) acetic acid (to lyse red blood cells) and trypan blue exclusion. Cells were seeded at a density of $133,333 \mathrm{cells} / \mathrm{cm}^{2}$ and cultured under normoxic conditions $\left(37{ }^{\circ} \mathrm{C}\right.$ in a humidified atmosphere with $5 \% \mathrm{pCO}_{2}$ and $20 \% \mathrm{pO}_{2}$ ). After 10 days of culture, media was removed and flasks were washed twice with $10 \mathrm{ml}$ of PBS. Cells were then fixed with $2 \%(\mathrm{w} / \mathrm{v})$ PFA for $15 \mathrm{~min}$ at RT. The cells were washed again in PBS and incubated with $1 \%(\mathrm{w} / \mathrm{v})$ crystal violet (Sigma) for 2 min at RT. Crystal violet was removed and flasks were washed under running tap water for $10 \mathrm{~min}$. Flasks were left to fully dry overnight before imaging. Stained colonies were then counted using ImageJ software.

\subsection{Histological analysis}

The samples were fixed in $10 \%$ formalin overnight and decalcified using 'Decalcifying Solution-Lite' (Sigma) for approximately 1 week. Samples were frequently X-rayed to determine if any mineral content remined. When no mineral was visible, the sam- 
Table 1

3D Bioprinting processing parameters for each bioink.

\begin{tabular}{|c|c|c|c|c|}
\hline & FibGel & GelMA & Alginate only & AlgGel \\
\hline Printing Temperature & $30^{\circ} \mathrm{C}$ & $28{ }^{\circ} \mathrm{C}$ & $22{ }^{\circ} \mathrm{C}$ & $30{ }^{\circ} \mathrm{C}$ \\
\hline Polymer Concentration & $\begin{array}{l}\text { Fibrinogen } 30 \mathrm{mg} / \mathrm{mL} \text {, } \\
\text { gelatin } 30 \mathrm{mg} / \mathrm{mL}, \mathrm{HA} 3 \\
\mathrm{mg} / \mathrm{mL}, 10 \% \text { glycerol }\end{array}$ & $\begin{array}{l}5 \%(w / v) \text { GelMA, } 0.05 \% \\
\text { Irgacure }\end{array}$ & $\begin{array}{l}2.45 \%(\mathrm{w} / \mathrm{v}) \mathrm{RGD}-\gamma \\
\text { alginate and } 18 \mathrm{mM} \mathrm{CaCl} \\
\end{array}$ & $\begin{array}{l}2.45 \%(\mathrm{w} / \mathrm{v}) \mathrm{RGD}-\gamma \text { alginate in gelatin } \\
21 \mathrm{mg} / \mathrm{mL}, \mathrm{HA} 2.1 \mathrm{mg} / \mathrm{mL}, 7 \% \text { glycerol } \\
\text { and } 18 \mathrm{mM} \mathrm{CaCl} 2\end{array}$ \\
\hline $\begin{array}{l}\text { Post-crosslinking } \\
\text { Mechanism }\end{array}$ & $\begin{array}{l}\text { Thrombin bath } 20 \mathrm{U} / \mathrm{mL} \\
\text { (30 min) }\end{array}$ & UV light (15 min) & $\begin{array}{l}\text { Calcium chloride } 100 \mathrm{mM} \\
\text { bath }(30 \mathrm{~min})\end{array}$ & $\begin{array}{l}\text { Calcium chloride } 100 \mathrm{mM} \text { bath ( } 30 \\
\text { min) }\end{array}$ \\
\hline Extrusion Pressure & $0.05 \mathrm{MPa}$ & $0.1 \mathrm{MPa}$ & $0.2 \mathrm{MPa}$ & $0.1 \mathrm{MPA}$ \\
\hline
\end{tabular}

ple was considered decalcified. Samples were then dehydrated in graded series of ethanol solutions (70\% - 100\%), cleared in xylene, and embedded in paraffin wax (all Sigma-Aldrich). Sections ( $5 \mu \mathrm{m}$ ) were rehydrated in graded series of ethanol concentrations and stained with haematoxylin and eosin, $1 \%(\mathrm{w} / \mathrm{v})$ alcian blue $8 \mathrm{GX}$ in $0.1 \mathrm{M} \mathrm{HCl}$ to assess sulphated glycosaminoglycan (sGAG) content with a counter stain of $0.1 \%(\mathrm{w} / \mathrm{v})$ nuclear fast red to assess cellular distribution, $0.1 \%(\mathrm{w} / \mathrm{v})$ picrosirius red to assess collagen distribution, $0.2 \%(\mathrm{w} / \mathrm{v})$ Safranin 0 to assess sGAG content post-implantation and Goldner's trichrome (Groat's iron haematoxylin, Fuchsine, Orange G, Fast Green) for visualising bone (all from Sigma). Slides were then imaged using an Aperio ScanScope slide scanner and evaluated for vessel infiltration by counting vessels visible across an entire section using Aperio ImageScope and ImageJ software. Bone formation was assessed using ImageJ software. It should be noted that PCL is cleared during the tissue processing and leaves empty spaces in constructs as a result. Immunostaining for human CD31 (abcam) was carried out by the Liver Histopathology Laboratory in King's College Hospital, London.

\subsection{Statistical analysis}

Statistical analyses were performed using GraphPad Prism (version 6) software. To analyse variance between groups, two-way ANOVA was used with Tukey post-hoc test. Numerical and graphical results are displayed as mean \pm standard deviation unless otherwise stated. Significance was accepted at a level of $p<0.05$.

\section{Results}

\subsection{Comparison of bioink printability and cell viability post-printing}

We first sought to compare the printability of three candidate bioinks, namely a fibrin-based bioink, a $\gamma$-irradiated-RGD alginatebased bioink, and a GelMA-based bioink (Fig. 2). To evaluate their printability, spreading ratios were compared for each formulation as previously described $[26,34]$. The filament spreading ratio is defined as the width of the printed filament divided by the needle diameter. Lower spreading ratios, approaching the ideal ratio of 1 , are desirable to allow the fabrication of cell-laden hydrogel structures with high accuracy. A detailed description of the hydrogel printing properties can be found in Table 1, including the printing parameters adopted for each hydrogel formulation. Unless fibrinogen (the precursor to fibrin) was first combined with a temporary supporting gel it was found to be unprintable. Mixing fibrinogen with a temporary gelatin-based carrier gel enabled its printing and resulted in the fibrin-based bioink (herein termed FibGel) having the lowest spreading ratio $(1.76 \pm 0.09$; Fig. $2 \mathrm{~A} \& \mathrm{~B})$. Without the use of a temporary gelatin-based carrier gel, the $\gamma$-irradiated-RGD alginate had a very high spreading ratio $(6.9 \pm 1.12)$, with inclusion of the gelatin-based support (herein termed AlgGel) reducing this by $64.8 \%(2.40 \pm 0.21)$. GelMA had the second lowest spreading ratio $(2.28 \pm 0.19)$ and extruded more consistently (as evident by the lowest standard deviation) than all other hydrogels (Fig. 2A\&B).
The elimination of the gelatin from the AlgGel and FibGel following crosslinking was confirmed using a hydroxyproline assay after $24 \mathrm{~h}$ in vitro (Supplementary Figure 1).

Cell viability during and after 3D bioprinting is dependent on the shear stress experienced during extrusion, which in turn is dependent on the viscosity of the solution, the applied pressure and the needle diameter [35]. In addition, the post-printing bioink crosslinking mechanisms can further influence cell viability. Since the solution viscosity, applied pressure and post-crosslinking mechanism varied across the three hydrogels, cell viability was evaluated post-printing for each bioink. All bioinks supported high levels of cell viability (>70\%; Fig. 2C). This indicates that 3D structures containing viable endothelial cells could be 3D bioprinted using each bioink. The levels of cell viability presented here are in agreement with the literature for similar printing systems [26,36-38].

\subsection{Comparison of endothelial sprouting in gelma, alginate and fibrin based bioinks}

To evaluate the potential of each bioink to facilitate endothelial sprouting, they were loaded with HUVECs and simple cylindrical constructs were 3D bioprinted (4 mm height, $4 \mathrm{~mm}$ diameter). These were then cultured for up to 7 days in the presence of VEGF (50 ng/mL) and then evaluated for microvessel formation using confocal microscopy. By day 3, no endothelial sprouting was seen in either the AlgGel or GelMA bioink. In the FibGel bioink, however, the endothelial cells had migrated towards each other and began to elongate and align by day 3 . By day 5 , these HUVECs had formed microvessels which began to sprout forming multidirectional networks. By day 7, a microvessel network was observed throughout these constructs (Fig. 2D). In the GelMA constructs, no evidence of endothelial sprouting was seen until day 7 , at which point there was evidence of rapid proliferation and inconsistent vessel formation. These rapidly proliferating cells appeared at times to form a monolayer architecture across the newly formed spaces in the degrading bioink as opposed to elongated microvessels. Over the course of 7 days, there was no endothelial proliferation or sprouting observed in the AlgGel bioink, presumably due to the inability of HUVECs to degrade the surrounding alginate gel, which is vital for vasculogenesis to take place. The average vessel length within all three bioinks was quantified using ImageJ, which revealed that the fibrin-based bioink had significantly higher average vessel lengths and the most consistent growth of microvessels over time (Fig. 2E). The percentage area endothelialised was calculated for each bioink by dividing the sum of the cell area by the total area (Fig. 2F). Overall a more controlled, consistent establishment of a microvessel network was observed within the FibGel bioink. Between day 3 and day 5, the area of endothelialisation did not increase, whilst the vessel length did, suggesting plexus remodelling during this time. Given the consistency and the superiority of the fibrin-based bioink to produce a premature vascular network in vitro, it was chosen as the preferred bioink for all future studies. 
A

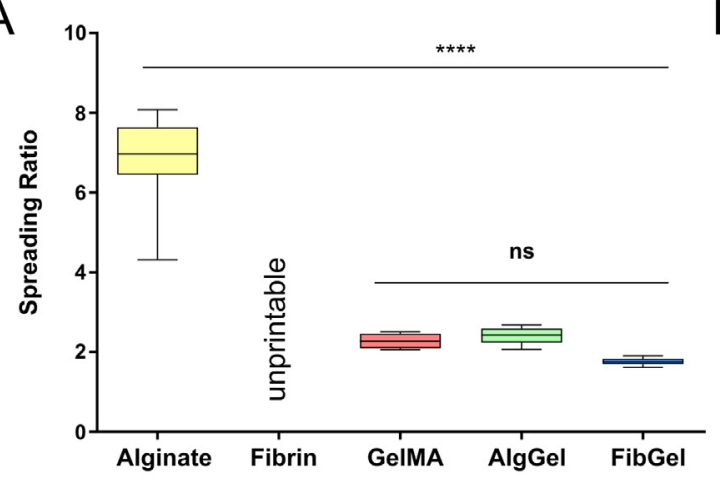

B

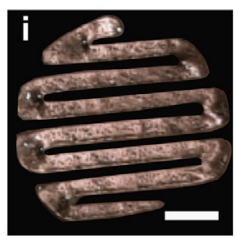

iii

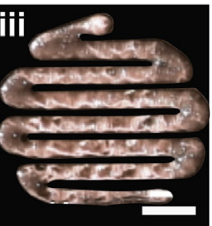

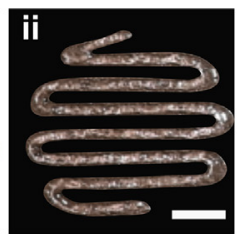

iv

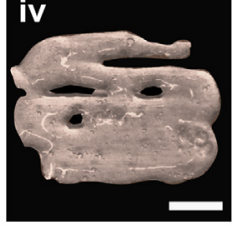

C
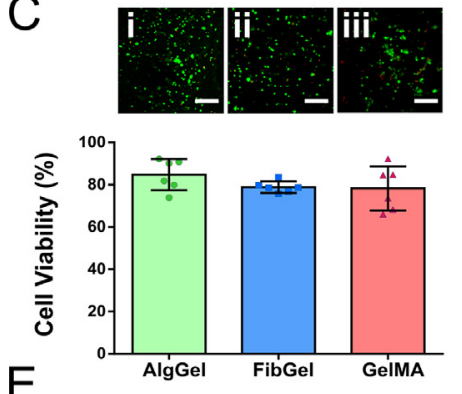

E
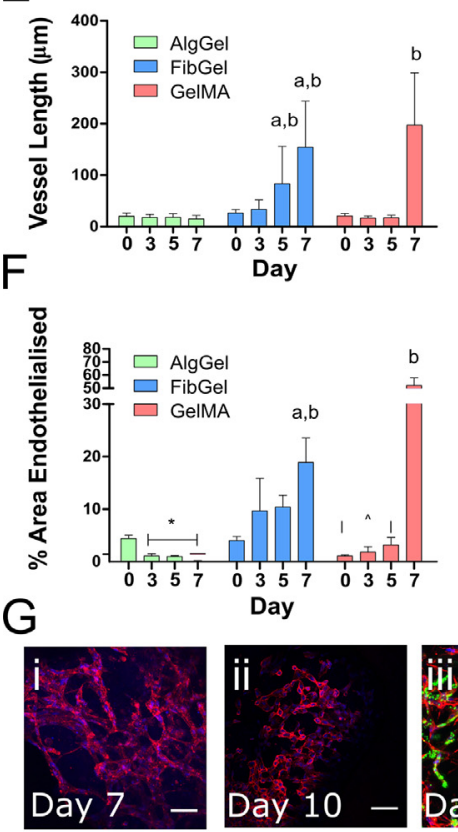

FibGel

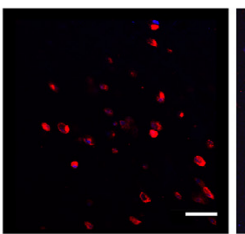

GelMA

D AlgGel
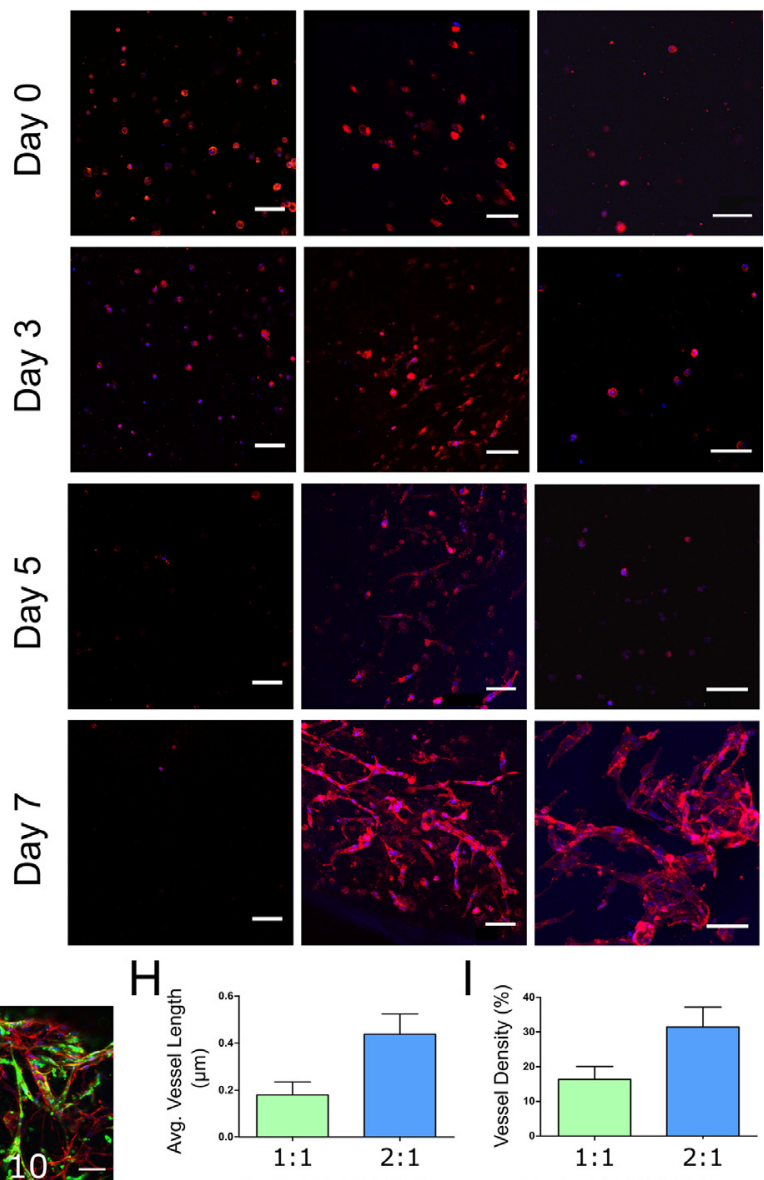

Ratio EC:hBMSCs

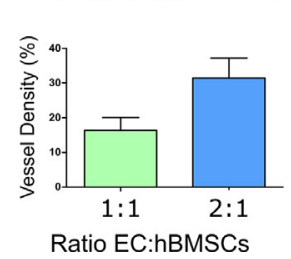

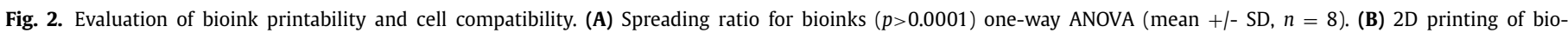

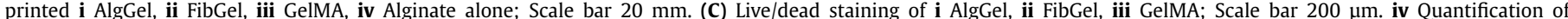

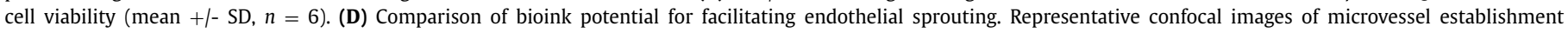

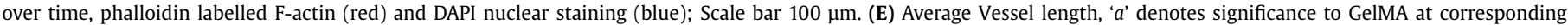

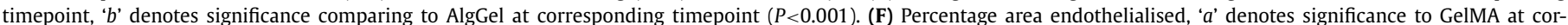

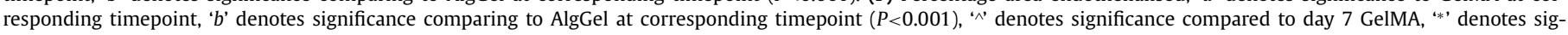

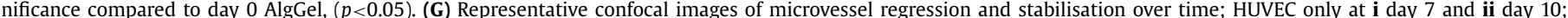

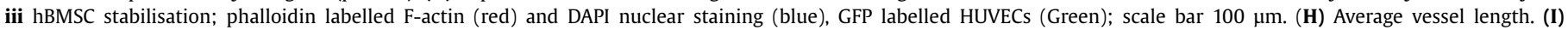
Vessel density (Values are the mean $\pm \mathrm{SD}, n=3$ ). 
Between day 7 and 10 of in vitro culture, the engineered microvessel networks began to regress as evidenced by phalloidin staining (Fig. 2G). This is a phenomenon seen during innate vessel formation where pericytes are vital to vessel function. Pericytes not only serve as scaffolding to support the vascular network architecture, but also communicate with endothelial cells by direct physical contact and paracrine signalling pathways [39]. In vitro, the importance of a supporting cell type has been shown in multiple studies to be necessary for the successful formation of a perfusable network. Multiple cell types have been shown to stabilise endothelial networks, including fibroblasts [40], 10T1/2 mesenchymal precursor cells [41], and tri-cultures of myoblasts and embryonic fibroblasts [42]. The inclusion of these supporting cells ensures vessel integrity. In this study, the decision to include hBMSCs as the supporting cell type was inspired by the emerging argument that all MSCs are pericytes [43] and have been shown in literature to be able to mediate vascularisation by secreting angiogenic factors such as vascular endothelial growth factor (VEGF), fibroblast growth factor-2 (FGF-2), angiopoietin 1 (Ang-1), and epidermal growth factors (EGF) [44]. The inclusion of hBMSCs into the fibrin-based bioink system enabled extended microvessel stability for up to 2 weeks for 2 different ratios of HUVECs to hBMSCs, 1:1 and $2: 1$, which both resulted in the stabilisation of the microvessel network beyond 10 days in culture. Using confocal imaging in conjunction with software for quantitative analysis of angiogenesis (Angiotool [30]), the vessel density and average vessel length was calculated for both co-culture ratios (Fig. 2H\&I). When comparing both co-cultures, there was a trend toward both higher vessel density and average vessel length in the 2:1 HUVEC:hBMSC co-culture, although these differences were not statistically significant. Based on this observation, the 2:1 HUVEC:hBMSC co-culture was chosen for subsequent in vivo studies.

\subsection{In vivo assessment of prevascularised $3 D$ bioprinted constructs}

To determine whether the in vitro establishment of a microvessel network within a bioprinted construct prior to its implantation would result in more rapid vascularisation in vivo, bioprinted FibGel constructs were next implanted subcutaneously into nude mice. A solid, PCL sheath was designed to provide mechanical support for the bioink, with the two ends of this cylindrical sheath left open to encourage unidirectional in-growth of host vessels and anastomosis with the engineered vasculature. One of following four cell populations was bioprinted into this sheath using the FibGel bioink: (1) HUVECs alone, (2) hBMSCs alone, (3) a 2:1 coculture of HUVECs and hBMSCs and (4) a cell free control. These 4 groups were exposed to one of two conditions; the first involved an additional week of culturing in endothelial growth media supplemented with VEGF to establish a microvascular network prior to implantation (these groups are herein termed Prevascularised implants); the second involved the immediate implantation of the cell-laden constructs (these groups are herein termed Cellularised implants) into the mice without any in vitro culture (Fig. 3A). The implants were resected at either 1 week or 2 weeks postimplantation. Macroscopically, the prevascularised implants which had been cultured for 7 days prior to implantation appeared to be more vascularised compared to all other groups (Supplementary Figure 2). Microscopically, however, these apparent differences in vascular invasion did not always translate to the presence of blood vessels inside the body of the printed implants. Frequently there was evidence of red blood cells without the presence of a vessel wall. For all vessel analysis, a vessel was defined by the presence of red blood cells surrounded by dense nuclei. At day 7 , the only group which contained any vessels was the prevascularised construct produced using a co-culture of HUVECs and hBMSCs (Fig. 3F). By day 14, some constructs in the cultured HUVEC only group and the cell free group had become vascularised, but the prevascularised constructs persisted as the group supporting the highest level of vascularisation in vivo (Fig. 3G). This prevascularised co-culture regime was therefore selected as the strategy to prevascularise implants for the treatment of large bone defects.

\subsection{D Bioprinting of prevascularised constructs for large bone defect healing}

To determine if prevascularising a bioprinted construct enhances its therapeutic potential, the FibGel bioink (containing HUVECs and hBMSCs) was deposited into 3D printed nHA coated PCL scaffolds and maintained in culture for 7 days prior to its implantation into critically-sized ( $5 \mathrm{~mm}$ long) defects in the femur of immunosuppressed rats (Fig. 4). Porous PCL scaffolds were fabricated using fused deposition modelling (FDM; Fig. 4A). Scaffold dimensions were selected to ensure an accurate press-fit into the bone defect during surgical implantation. The PCL scaffolds were surface coated with nano hydroxyapatite (nHA) prior to bioprinting the prevascular network to further promote osteogenesis. Scanning electron microscopy (SEM) imaging confirmed the presence of the nHA coating, revealing a rod-like/needle architecture. Each nanoneedle was approximately $100 \mathrm{~nm}$ in length and $37 \mathrm{~nm}$ in diameter (Fig. 4B). To bioprint the prevascularised (PV) scaffolds, the FibGel bioink containing HUVECs and hBMSCs $\left(3 \times 10^{6}\right.$ cells $/ \mathrm{mL}$ and $1.5 \times 10^{6}$ cells/mL respectively) was deposited into the $\mathrm{nHA}$ coated PCL scaffolds using a 'Z-printing' technique [10]. These scaffolds were cultured for 7 days in the presence of VEGF $(50 \mathrm{ng} / \mathrm{mL})$ to allow for the formation of a microvascular network within the scaffold (Fig. 4B iv). These constructs were then implanted into critical-sized $(5 \mathrm{~mm})$ defects created in the femurs of Wistar Han rats (Fig. 4C\&D). To enable the implantation of human cells, rats were administered daily subcutaneous injections of an immunosuppressing drug cocktail containing FK506 and SEW2871 for 3 weeks after implantation, as previously described [32,33].

2 weeks post-implantation, $\mu \mathrm{CT}$ angiography was used to quantify and visualise vascular network formation in the bone defects. The PV scaffolds supported significantly higher total vascular volume and vessel connectivity compared to the scaffold alone (Fig. 5Aii \& iii). 3D reconstructions of $\mu \mathrm{CT}$ angiography scans revealed extensive vascular networks had formed following implantation of the PV scaffolds, with large vessels diameters of up to $0.35 \mathrm{~mm}$ detected within the defects (Fig. 5Ai). Additionally, the vascular network which formed in the PV scaffold group tended to do so in dense bunches at the periphery of the defect site. This may indicate inosculation of host vasculature with the implanted vasculature.

$\mu \mathrm{CT}$ analysis of animals at 2 weeks post-implantation was carried out to assess early bone formation (Fig. 5B). The PV scaffold supported significantly higher levels of new bone formation compared to the Scaffold only group at this early timepoint (Fig. 5Bii) and significantly higher bone volume fraction (Fig. 5C). H\&E staining revealed high cell infiltration in both groups. Positive Safranin O staining indicated that neoosseous tissue was, at least in part, being formed through endochondral ossification (Fig. 5Ci). Quantification of positive Safranin O staining revealed a non-significant trend toward larger cartilage area in the PV group (Fig. 5Cii). Goldner's trichrome staining indicated new bone formation predominantly at the periphery of the defect area in both groups (Fig. 5Ci). Quantification of positive Goldner's trichrome staining revealed no significant difference in the percentage of newly forming bone between the two groups at this timepoint (Fig. 5Ciii), despite the significant difference in mineralised bone tissue detected by $\mu \mathrm{CT}$.

$\mu \mathrm{CT}$ analysis was performed on animals 6 - and 12 -weeks postimplantation to visualise and quantify bone formation within the defects (Fig. 6A). There were no significant differences in total bone 
A

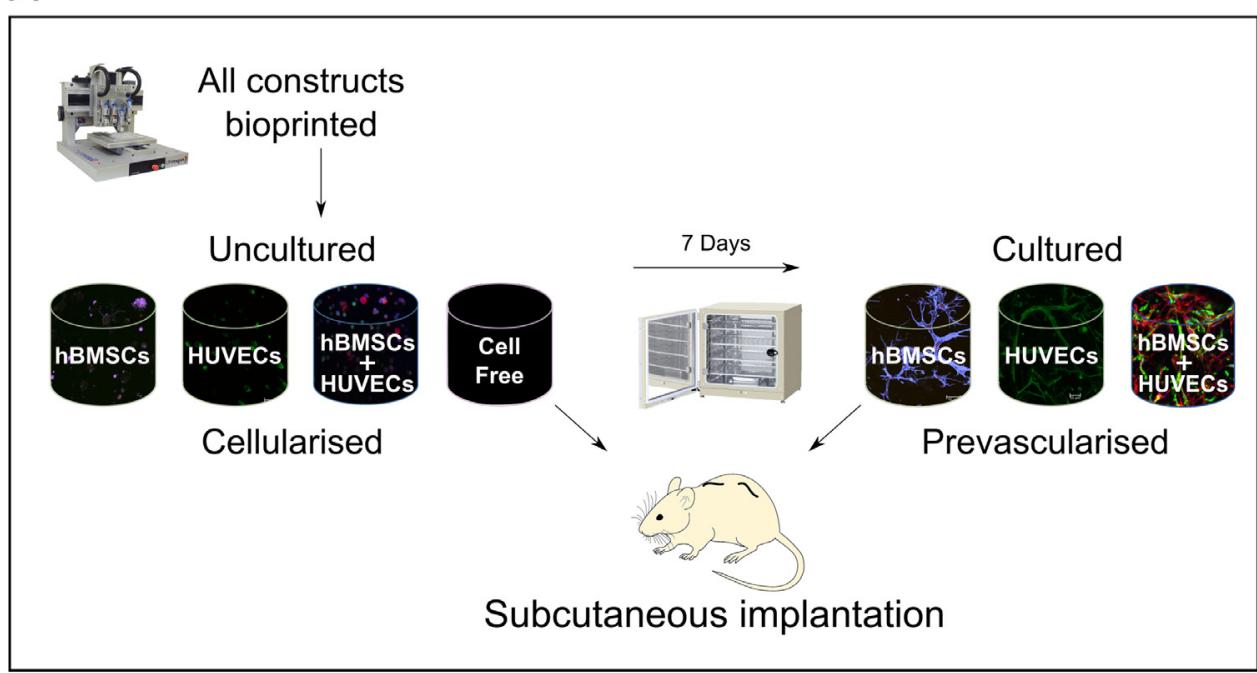

B
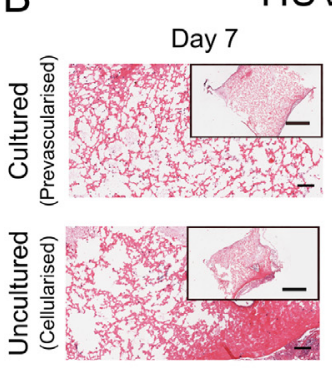

D
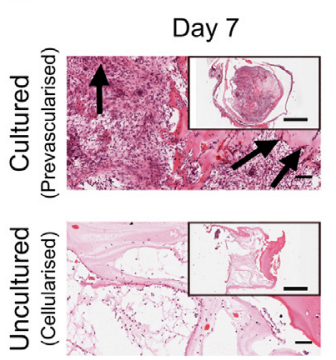

HUVEC only

Day 14
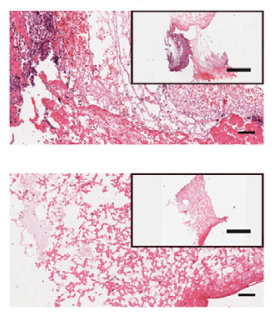

BMSC

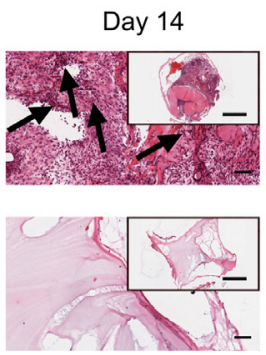

C
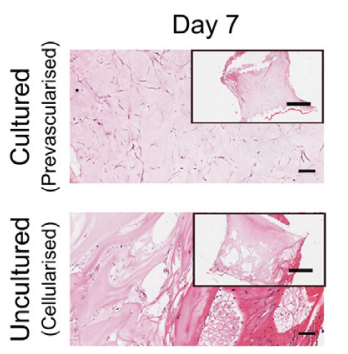

$\mathrm{E}$

\section{Cell free}

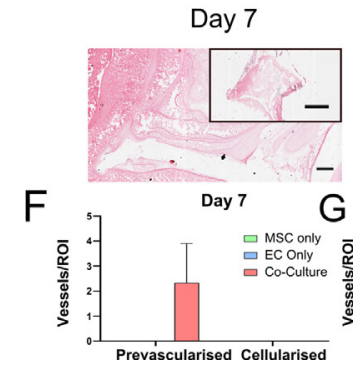

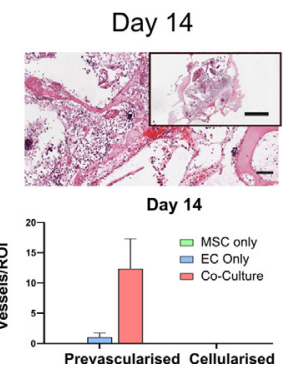

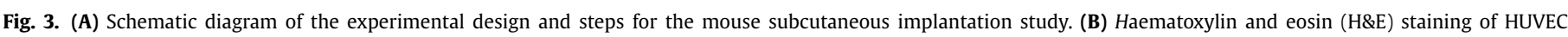

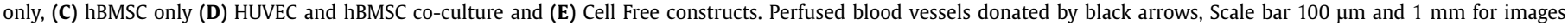
and inset images, respectively. (F) Vessels per construct at day 7 and (G) day 14 , ( $n=9$ mean \pm SEM).

volume or percentage bone fraction between the two groups at either timepoint, although there was a trend toward higher levels of bone volume in the PV scaffold group compared to the Scaffold only group (mean $11.45 \mathrm{~mm}^{3}$, SEM $2.65 \mathrm{~mm}^{3}$ versus mean $24.94 \mathrm{~mm}^{3}$, SEM $5.97 \mathrm{~mm}^{3}$ ) (Fig. $6 \mathrm{~B} \& \mathrm{C}$ ). There was no differences in bone mineral density between groups at either timepoint (6 weeks: $888.46 \mathrm{mgHA} / \mathrm{cm}^{3}$ versus $863.2 \mathrm{mgHA} / \mathrm{cm}^{3}$ and 12 weeks: $921.9 \mathrm{mgHA} / \mathrm{cm}^{3}$ versus $935.79 \mathrm{mgHA} / \mathrm{cm}^{3}$; data not shown). A feature of bone healing in the rat model was the significant animalto-animal variability in the levels of new bone formation in each group. To explore this further, we performed a colony forming unit (CFU) assay on bone marrow harvested from the contralateral femur of animals, which revealed that those animals displaying superior healing had higher numbers of CFUs than their poorer healing counterparts (Supplementary Figure 3). Despite this finding, there was no significant correlation between bone volume and CFU number, with a number of animals with very high numbers of CFUs displaying low levels of bone regeneration.
Histological evaluation of the defect sites was carried out afterwards to evaluate the neotissue which had formed within the implanted scaffolds after 12 weeks (Fig. 6F). H\&E staining after 12 weeks revealed bone formation within all groups. Interestingly, positive Safranin O staining was found at the centre of multiple defects in the PV scaffold group, indicating bone formation was still ongoing in these defects and was proceeding through an endochondral ossification pathway. However, this was highly variable, and quantification did not reveal a significant difference in cartilage tissue formation between the two groups (Fig. 6D). At this later time point, there were no significant differences in vessel density (Fig. 6E), with CD31 positive vascular structures observed through the defects (Supplementary Figure 4). Goldner's trichome staining indicated a sharp interface between the defect and surrounding bone tissue in the Scaffold only group. In the PV scaffold group, there was substantial new bone formation and evidence of integration between the host bone and the neotissue that formed within the scaffold, with no apparent interface between the two. 
A

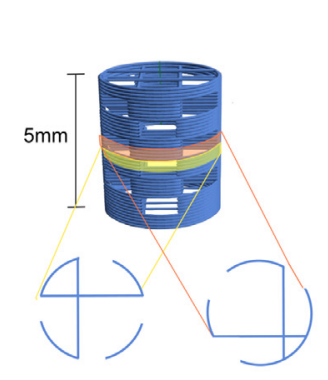

C

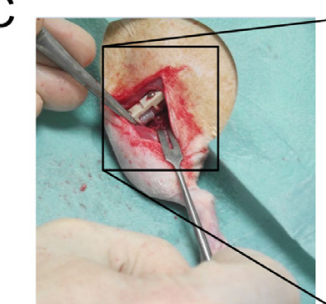

B
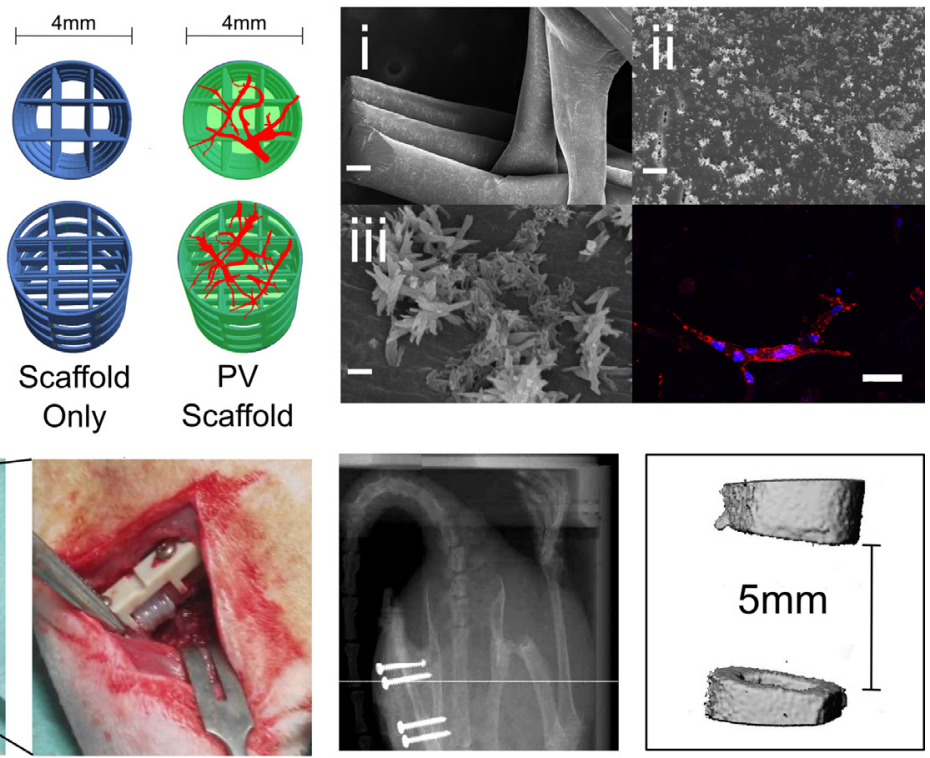

D

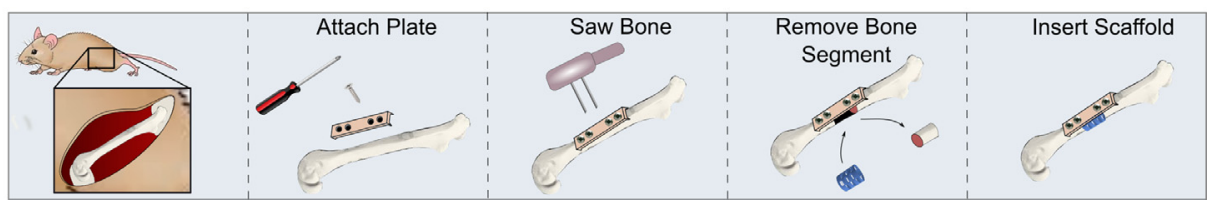

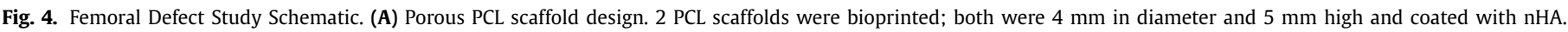

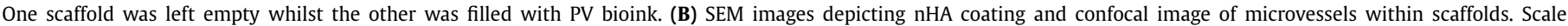

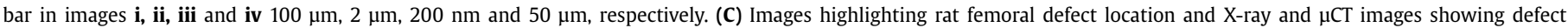
dimensions. (D) Schematic outlining surgical procedure.

This may further indicate that bone formation was still in progress in the PV scaffold group, whereas regeneration had halted in the Scaffold only group resulting in the capping of bone ends (Fig. 6F).

\section{Discussion}

This study describes the development of a 3D bioprinting strategy to fabricate prevascularised tissues with the capacity to accelerate the vascularisation of large tissue defects. A screen of several bioinks revealed that a fibrin-based bioink best supported the establishment of a microvessel network within bioprinted constructs in vitro. Bioprinted constructs containing microvessel networks generated using HUVECs and hBMSCs in vitro supported vessel formation in vivo following their subcutaneous implantation into mice. The incorporation of this prevascularising bioink within 3D printed scaffolds was also shown to enhance the vascularisation of critically-sized bone defects, which correlated with increased early bone formation.

There are multiple studies in the literature demonstrating the capacity of hydrogels to facilitate angiogenesis $[15,45,46]$. However, many of these hydrogels are not directly compatible with bioprinting technologies. In this study, we first demonstrated that three hydrogels (alginate, fibrin and GelMA) commonly used in tissue engineering can be successfully bioprinted, but that this often necessitated the inclusion of a temporary agent (gelatin) to increase the viscosity of the ink. Endothelial cells remained viable within these constructs post-printing. However further analysis revealed that only the fibrin-based bioinks were capable of facilitating the controlled establishment of a microvessel network in vitro over 7 days of culture. A microvascular network was rapidly established in the GelMA bioink between day 5 and 7 of culture, which correlated with a more inconsistent vascular architecture. No obvious microvessel network was established in the alginate based bioink. Although alginate is widely used for tissue engineering applications, the finding that the HUVECs were unable to establish a microvessel network within the alginate bioink was not unexpected. It has been shown that the production of proteolytic enzymes, known as Matrix Metalloproteinases (MMPs), is a vital step in angiogenesis that facilitates the local remodelling of the extracellular matrix (ECM) and endothelial cell invasion [47]. Alginate is the main structural component of marine brown algae and, although highly biocompatible, is impervious to cleavage by mammalian enzymes. Modifications have been made to the alginate used in this study [22], involving gamma irradiation, which reduces its molecular weight and accelerates passive degradation of the hydrogel, as well as the immobilisation of the cell adhesion peptide sequence arginine-glycine-aspartate (RGD). However, the encapsulated cells were unable to actively degrade their surrounding environment. This resulted in the lack of cell sprouting observed in response to the VEGF mediated endothelial activation. For alginate to be suitable for such prevascularisation strategies, further alginate modifications must be undertaken, such as the inclusion of the MMPsensitive domains (e.g. the peptide Pro-Val-Gly-Leu-Iso-Gly [48]). From the results of this study, GelMA bioinks show some promise for the inclusion in angiogenic tissue engineered constructs. During pilot studies, polymer concentrations were varied to investigate optimum sprouting conditions. A higher percentage of GelMA (10\%) was found to inhibit endothelial sprouting, whereas lower percentages of $3 \%$ were too low to form stable hydrogels (data not shown). It should also be noted that the protocol undertaken in this study has been shown to support a degree of methacrylation of approximately 75\% [24,25], although there was no further investigation into the optimal degree of methacrylation for supporting the establishment of microvascular networks. It has been shown that the 

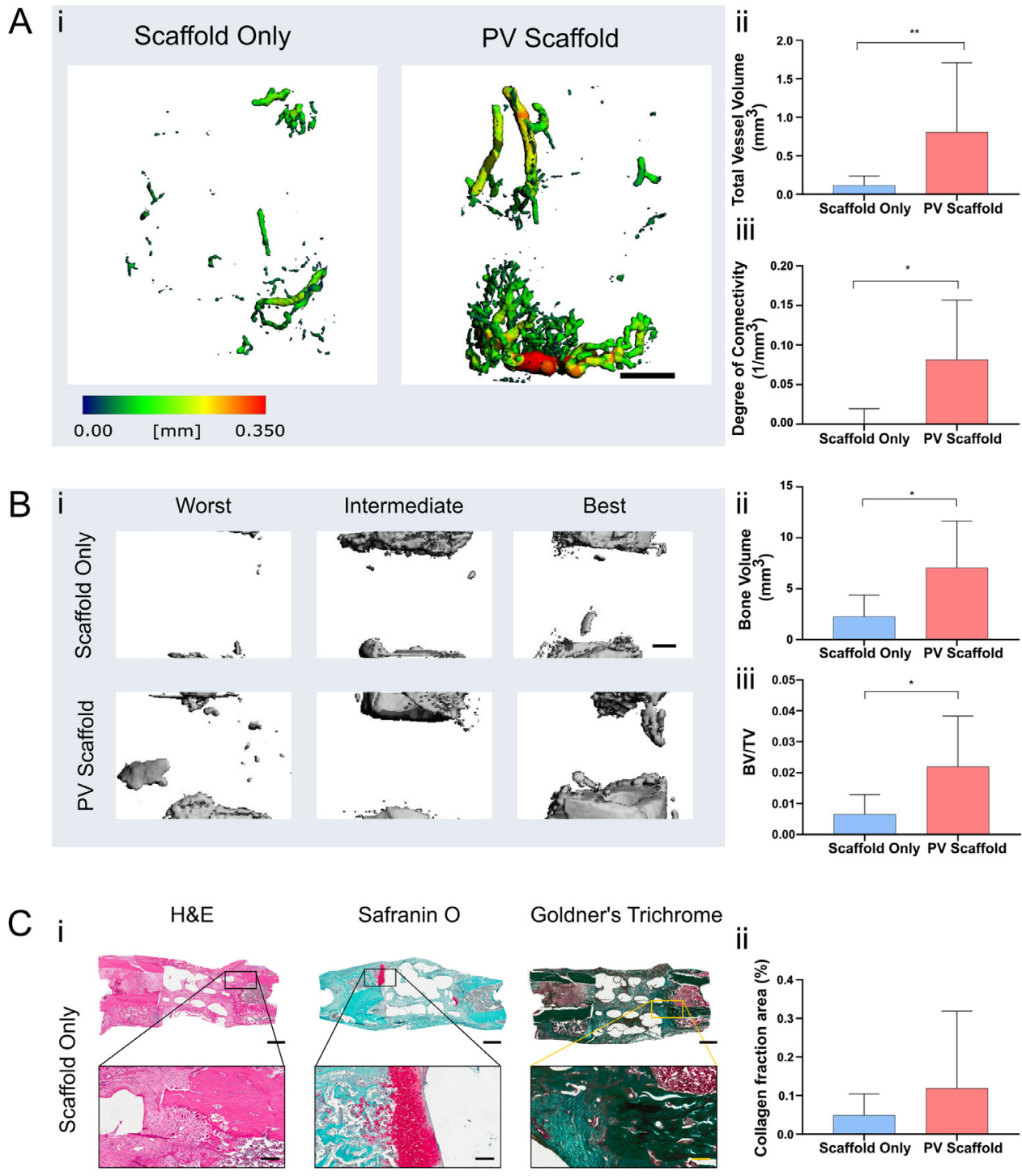

Goldner's Trichrome
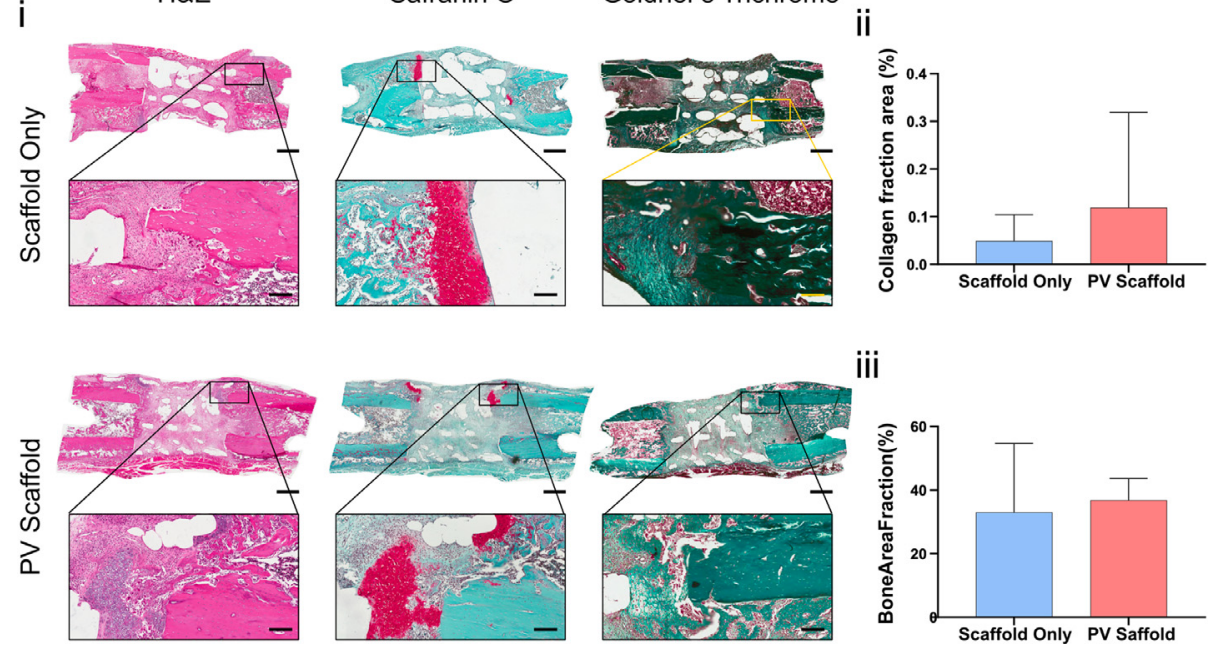

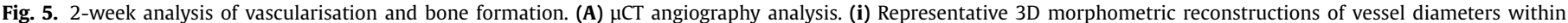

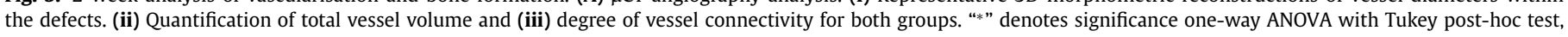

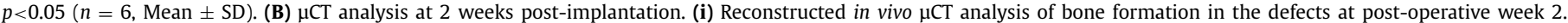

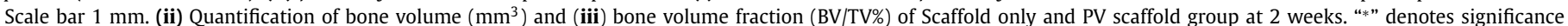

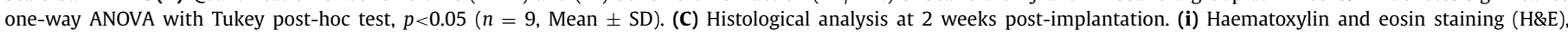

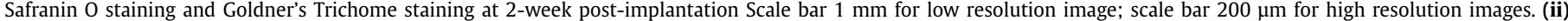
Cartilage area fraction and (iii) New bone area fraction $(n=9$, Mean \pm SD).

degree of functionalisation of GelMA can have a profound effect on cell spreading, with higher functionalisation resulting in a less spread cell phenotype [49]. Considering this, future studies should explore whether lowering the degree of methacrylation would improve vessel formation within GelMA based bioinks. Another important factor that we did not consider in this study was potential differences in the mechanical properties of the different hydrogel bioinks. Previous studies have shown that matrix stiffness regu- lates endothelial cell sprouting and the vascular phenotype [5052]. Our focus was on designing a prevascularisation technique which would be compatible with bioprinting, so the printability of the inks was a key determining factor when determining the composition of the different hydrogels. Although the authors acknowledge that alterations to the polymer density could have improved the sprouting potential of these bioinks, it would also have affected their printability. Emerging bioprinting strategies such as 
A
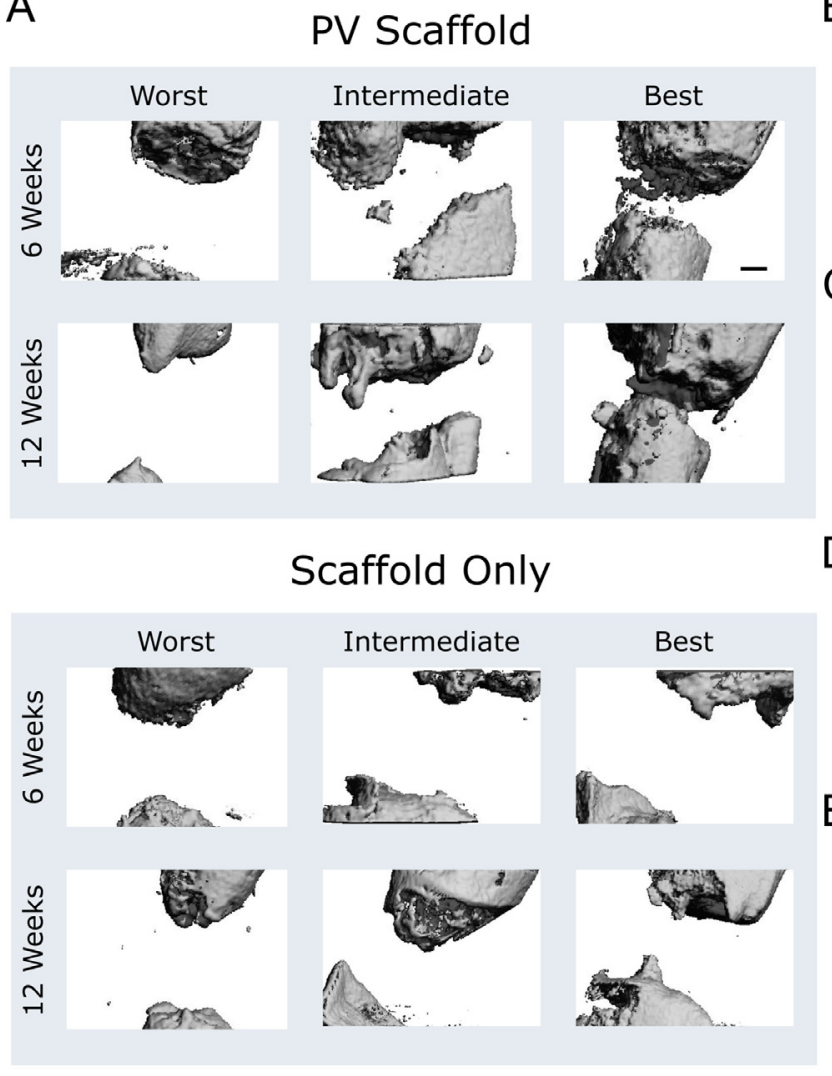

$\mathrm{F}$
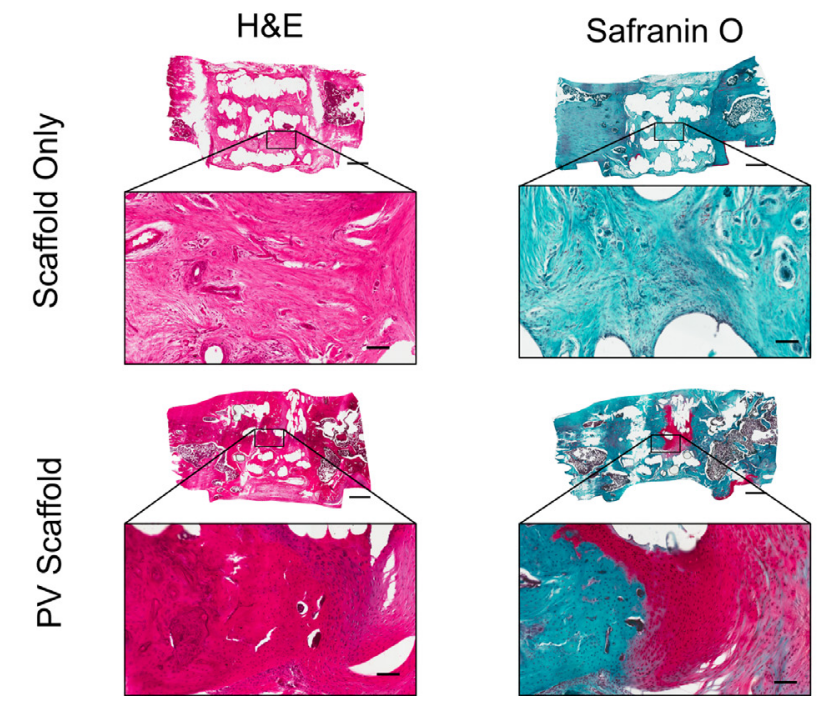

B

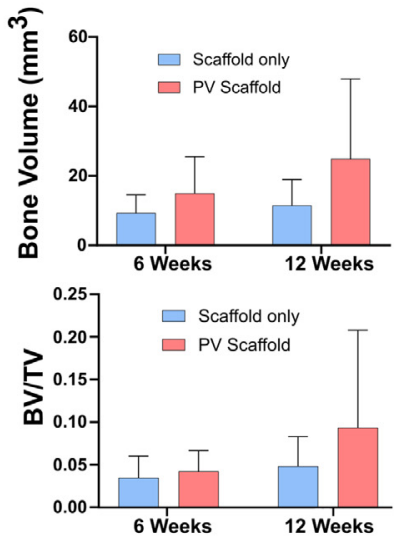

$\mathrm{D}$

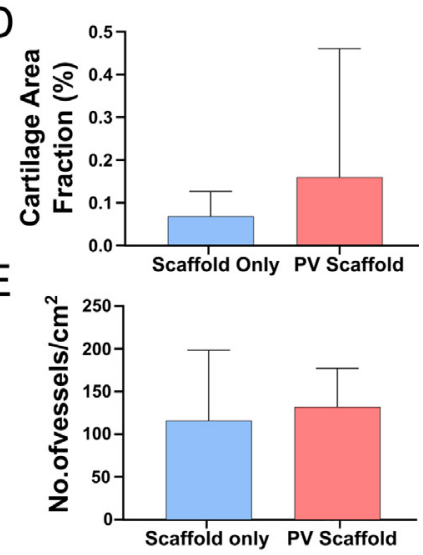

Goldner's Trichrome
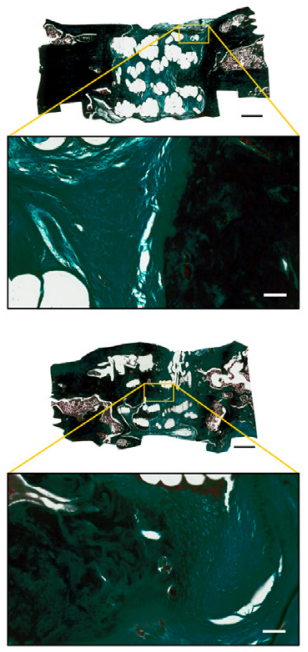

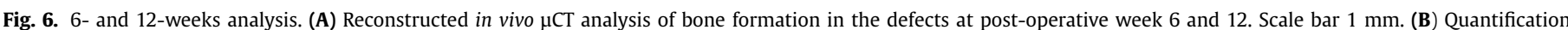

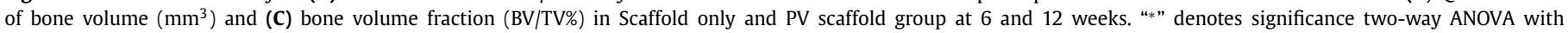

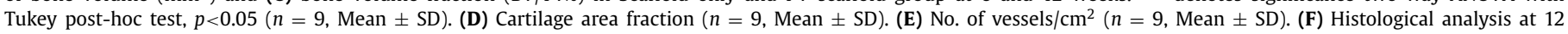

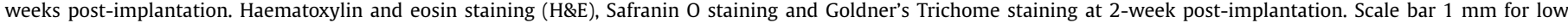
resolution image; scale bar $100 \mu \mathrm{m}$ for high resolution images.

the freeform reversible embedding of suspended hydrogels (FRESH) technique $[53,54]$ could potentially address such concerns.

Bioprinted constructs containing a 2:1 ratio of HUVECs and hBMSCs were found to support the development of a persistent microvascular network in vitro and robust blood vessel development in vivo. Native microvessels are surrounded by sparsely distributed perivascular cells which support the vessel physically (like a type of scaffolding) whilst simultaneously communicating with endothelial cells by direct contact and through paracrine signalling pathways [55]. It has also been suggested that during injury, pericytes can detach and differentiate into what is now sometimes defined as an MSC [56]. This MSC can then sense the microenvironment and respond through producing and secreting numerous bioactive molecules. This adaptability of MSCs has made them an attractive cell type for a multitude of applications such as tissue regeneration $[57,58]$, immunomodulation $[59,60]$ and cancer treatment $[61,62]$. They have also been used to help maintain the pattern of endothelial cell networks generated by laser-assisted bio- 
printing [63] and to support the development of vascular networks with defined architecture in bioprinted constructs [64]. It also makes them an attractive cell type for this study due to their ability to support vessel formation in vitro and by potentially contributing to bone tissue regeneration, although demonstrating the latter requires further study. Similar to the findings of other studies exploring co-cultures of different endothelial cells and support cells [65-69], the inclusion of hBMSCs into the fibrin-based gels enabled extended microvessel stability for up to 2 weeks in vitro for both a $1: 1$ and a 2:1 ratio of HUVECs:hBMSCs. The 2:1 coculture was selected for further in vivo analysis as it had shown a trend towards supporting the development of a denser vascular network in vitro. Further in vivo analysis revealed that the prevascularisation of bioprinted constructs, through the establishment of microvessels in vitro, led to a higher number of perfused vessels within the core of the construct following subcutaneous implantation into nude mice. Bioprinting the same cell population, and then implanting the construct immediately without a 7-day culture period to ensure prevascularisation, did not facilitate vessel formation in vivo. This demonstrates that the formation of bloods vessels within bioprinted constructs in vivo is dependent on the preculturing of HUVECs and hBMSCs in the presence of the angiogenic growth factor VEGF to establish a stable microvascular network in vitro prior to implantation.

The premise of prevascularisation is that inosculation between the implanted microvascular network and the host microvasculature occurs more rapidly than vessel ingrowth could occur, therefore reducing the time the implanted tissue takes to be perfused with a blood supply. The fate of graft endothelial cells during the process of inoculation is disputed. It has been shown through in situ hybridization studies that host vessels invaded full-thickness skin grafts along pre-existing channels which were formed through the regression of the graft vasculature [70]. Conversely, studies have shown direct inosculation of implanted microvasculature to host blood vessels. In one such study, scaffolds which had previously undergone in situ prevascularisation in GFP-transgenic mice were implanted into dorsal skinfold chambers of wildtype mice. Intravital fluorescence microscopy was then used to show inosculation of the intrinsic scaffold microvasculature to the host blood vessels [71]. These contradictory findings show that further studies are needed to understand the contribution that preformed vessels make to the vascularisation process in implanted constructs both in the study presented in this paper and others. In this study, human endothelial cell derived microvasculature was implanted into immune compromised murine models to prevent immune system recognition of foreign antigens. How such immune factors regulate the process of inosculation is unclear and further studies exploring different autologous and allogenic cell populations are required to translate such prevascularization strategies into the clinic.

Bioprinting of a microvascular network into nHA coated PCL scaffolds led to significantly higher levels of vascularisation within critical-sized femoral bone defects compared to the Scaffold only controls. $\mu \mathrm{CT}$ scans of the radiopaque $3 \mathrm{D}$ cast of the vasculature within the defect site revealed that the vessel architecture in the PV Scaffold treated animals was denser than in animals treated with the Scaffold only. This was particularly obvious at the interface between host bone and scaffold. This result may indicate inosculation between the implanted microvasculature and host vessels, whereby host vessels begin to fuse with the implanted microvasculature. However, this dense vasculature did not continue throughout the length of the scaffold. This may be due to a number of reasons. Firstly, it is possible the microvessel network was partially damaged during implantation, and/or parts of the network that were established in vitro regressed upon in vivo implantation. Another possible explanation for this finding relates to the limitations of the $\mu \mathrm{CT}$ angiography technique. In this study, few vessels below a diameter of $170 \mu \mathrm{m}$ were detected using $\mu \mathrm{CT}$ analysis. The average diameter of the implanted microvessels is below $50 \mu \mathrm{m}$, which although perfusable may be below the resolution of the X-ray contrast agent selected. As such, further optimisation may be needed to modify the Microfil perfusion mass in order to increase its working time and/or decrease its viscosity by altering the ratio of curing agent included in order to fully image the complete vessel network architecture in vivo.

The increase in vascularisation observed within femoral defects treated with the PV constructs correlated with significant increases in early bone formation compared to the Scaffold only controls. While no significant difference in bone formation was detected at later timepoints using $\mu \mathrm{CT}$, histological analysis of the defect site at 12 weeks post-implantation demonstrated an ongoing regenerative response in defects treated with the PV scaffolds, with a trend towards higher levels of bone formation following implantation of the prevascularised constructs. These findings demonstrate how bioprinting can be used to enhance vascularisation of a target defect site, and the therapeutic potential of such tissue engineering strategies for accelerating the regeneration of critical-sized bone defects. In recent years there has been considerable interest in prevascularising tissue engineering constructs using endothelial cells. Typically, these studies focus on in vitro microvessel formation $[16,72,73]$ and the do novo formation of vessels in vivo [41,74-77]. Investigation into the in vivo function of engineered capillary networks has been primarily undertaken in subcutaneous implantation models. These have shown that in vitro prevascularisation can lead to a more rapid vascularisation in vivo $[78,79]$. It has been proposed that this may be advantageous when combined with established bone tissue engineering strategies such as osteoinductive scaffolds [80]. However, limited studies have been carried out to investigate the effects of prevascularisation on in vivo bone formation. One study implanted preformed vascular networks into critical-sized calvarial defects in nude rats and found that such prevascularisation did not lead to significant differences in bone formation by 4 weeks [81]. In this study, the effect of prevascularisation on bone regeneration was studied over 12 weeks in a critical-sized femoral defect model in immunosuppressed rats. Although vascularisation of the defect site is a key component of tissue regeneration and was significantly improved by the implantation of a prevascularised scaffold, successful bone healing relies on a number of factors, including the delivery of osteoinductive cues. Although the presence of nHA on the PCL scaffolds has been shown to enhance osteogenesis [82], perhaps the prolonged benefits of prevascularisation would be more evident when included in a more potent osteogenic tissue engineered scaffold. While full defect bridging was not seen in either group after 12 weeks, the presence of cartilage in a subset of the PV scaffold group at 12 weeks may indicate that the healing process was continuing for those animals. Future studies should therefore explore the use of extended timepoints to evaluate the long-term effect of implanting prevascularised scaffolds into critical-sized bone defects.

Bioprinting technologies are constantly evolving and improving to meet the need for more controlled organisation in larger-scaled tissue analogues and to overcome limitations in conventional tissue engineering approaches. Lack of sufficient vascularisation is a major limitation in the field to date and numerous approaches using various bioprinting strategies are currently being explored in an attempt to overcome this hurdle. Early work in the field aimed to prevascularise tissue engineered constructs by creating hollow vessel-like channels within tissue engineered constructs [83-86]. Despite the many successes of these methods, most have been limited by the resolution attainable from extrusion-based fabrication technology. This restricts the vessel diameter size and fails to recapitulate the microvascular size and structure of native capil- 
lary beds. Advances in laser-assisted techniques has impacted the field, from the micropatterning of endothelial cells [87,88], to the engineering of constructs with microchannels as low as $10 \mu \mathrm{m}$ in diameter [89-91]. Photoablation can be used to directly produce microchannels within soft hydrogels. This method uses focalised pulsed lasers with sufficient energy to break down covalent bonds allowing for channels to be formed in any location within the gel and at any time. This method is compatible with a variety of hydrogels including collagen [89,92], PEGDA [93], PEGylated fibrinogen and silk protein hydrogel [94]. However, the cytocompatibility of some of these methods is impacted by the very high-energy light required. In a recent study, laser-assisted bioprinting was utilised to print HUVECs in situ into critical-sized calvaria bone defects and enhance vascularisation [95]. Although elegant, there may be challenges when translating such approaches to larger, load-bearing bone defects due to the low viscosity and stiffness of the collagen gel used. These studies demonstrate the need for numerous prevascularisation strategies in order to adapt to the problem at hand. For tissue engineering to achieve the goal of replacing human organs and tissues, we must have multiple, adaptable strategies in the biofabrication toolbox. The benefit of the bioprinting concept presented in this study is that it can be adapted to integrate with other bioprinting strategies. Furthermore, the thermo-reversible characteristics of this bioink enables the viscosity to be easily tailored. One limitation of our study was that we only had to bioprint relatively small constructs to treat segmental bone defects in our rodent model. Larger scale implants and in turn larger animal models are necessary to truly test the benefits of any prevascularisation technique.

\section{Conclusion}

The results from this study demonstrate that a fibrin-based bioink can facilitate the development of a stable primitive vascular network in vitro. Establishing microvessels within bioprinted tissues in vitro prior to their implantation led to enhanced vascularisation once implanted in vivo. This study further demonstrates, for the first time, that 3D bioprinting can be used to produce prevascularised scaffolds that enhance vascularisation of critically-sized bone defects. While applied here for bone regeneration, this technique could easily be adapted to prevascularise scaffolds used in the regeneration of any vascularised tissue or organ. It may be especially useful for the delivery of cells that are particularly sensitive to diminished oxygen or nutrient availability, such as pancreatic islet cells, or for the regeneration of ischemic tissues.

\section{Declaration of Competing Interest}

The authors declare that they have no known competing financial interests or personal relationships that could have appeared to influence the work reported in this paper.

\section{Acknowledgements}

This research was funded by the European Research Council (JointPrint; ERC-CoG509 2014-647004). The authors would like to thank the Liver Histopathology Laboratory, King's College Hospital, London, for their help with the CD31 immunostaining.

The data that support the findings of this study are available from the corresponding author, upon request.

\section{Supplementary materials}

Supplementary material associated with this article can be found, in the online version, at doi:10.1016/j.actbio.2021.03.003.

\section{References}

[1] R. Burdis, D.J. Kelly, 3D bioprinting hardware, in: Polym. Addit. Manuf., Springer International Publishing, Cham, 2019, pp. 161-186, doi:10.1007| 978-3-030-24532-0 8.

[2] J. Nulty, R. Schipani, R. Burdis, D.J. Kelly, Bioinks and their applications in tissue engineering, in: Polym. Addit. Manuf., Springer International Publishing, Cham, 2019, pp. 187-218, doi:10.1007/978-3-030-24532-0_9.

[3] U. Utzinger, B. Baggett, J.A. Weiss, J.B. Hoying, L.T. Edgar, Large-scale time series microscopy of neovessel growth during angiogenesis, Angiogenesis 18 (2015) 219-232, doi:10.1007/s10456-015-9461-X.

[4] A. Perets, Y. Baruch, F. Weisbuch, G. Shoshany, G. Neufeld, S. Cohen, Enhancing the vascularization of three-dimensional porous alginate scaffolds by incorporating controlled release basic fibroblast growth factor microspheres, J. Biomed. Mater. Res. 65A (2003) 489-497, doi:10.1002/jbm.a.10542.

[5] A.B. Ennett, D. Kaigler, D.J. Mooney, Temporally regulated delivery of VEGFin vitro andin vivo, J. Biomed. Mater. Res. Part A. 79A (2006) 176-184, doi:10. 1002/jbm.a.30771.

[6] J. Rui, M. Dadsetan, M.B. Runge, R.J. Spinner, M.J. Yaszemski, A.J. Windebank, $\mathrm{H}$. Wang, Controlled release of vascular endothelial growth factor using polylactic-co-glycolic acid microspheres: in vitro characterization and application in polycaprolactone fumarate nerve conduits, Acta Biomater. 8 (2012) 511-518, doi:10.1016/j.actbio.2011.10.001.

[7] L.S. Sefcik, C.E. Petrie Aronin, K.A. Wieghaus, E.A. Botchwey, Sustained release of sphingosine 1-phosphate for therapeutic arteriogenesis and bone tissue engineering, Biomaterials 29 (2008) 2869-2877, doi:10.1016/J.BIOMATERIALS. 2008.03.017.

[8] J.S. Miller, K.R. Stevens, M.T. Yang, B.M. Baker, D.-H.T. Nguyen, D.M. Cohen, E. Toro, A.A. Chen, P.A. Galie, X. Yu, R. Chaturvedi, S.N. Bhatia, C.S. Chen, Rapid casting of patterned vascular networks for perfusable engineered threedimensional tissues, Nat. Mater. 11 (2012) 768-774, doi:10.1038/nmat3357.

[9] K. Sakaguchi, T. Shimizu, S. Horaguchi, H. Sekine, M. Yamato, M. Umezu, T. Okano, In Vitro Engineering of Vascularized Tissue Surrogates, Sci. Rep. 3 (2013) 1316, doi:10.1038/srep01316.

[10] A.C. Daly, P. Pitacco, J. Nulty, G.M. Cunniffe, D.J. Kelly, 3D printed microchannel networks to direct vascularisation during endochondral bone repair, Biomaterials 162 (2018) 34-46, doi:10.1016/J.BIOMATERIALS.2018.01.057.

[11] D. Sharma, D. Ross, G. Wang, W. Jia, S.J. Kirkpatrick, F. Zhao, Upgrading prevascularization in tissue engineering: a review of strategies for promoting highly organized microvascular network formation, Acta Biomater. 95 (2019) 112-130, doi:10.1016/J.ACTBIO.2019.03.016.

[12] R.E. Unger, S. Ghanaati, C. Orth, A. Sartoris, M. Barbeck, S. Halstenberg, A. Motta, C. Migliaresi, J. Kirkpatrick, The rapid anastomosis between prevascularized networks on silk fibroin scaffolds generated in vitro with cocultures of human microvascular endothelial and osteoblast cells and the host vasculature, Biomaterials 31 (2010) 6959-6967, doi:10.1016/j.biomaterials.2010.05.057.

[13] M.W. Laschke, H. Mussawy, S. Schuler, A. Kazakov, M. Rücker, D. Eglin, M. Alini, M.D. Menger, Short-term cultivation of In Situ Prevascularized tissue constructs accelerates inosculation of their preformed microvascular networks after implantation into the host tissue, Tissue Eng. Part A. 17 (2011) 841-853, doi:10.1089/ten.tea.2010.0329.

[14] W. Zhu, X. Qu, J. Zhu, X. Ma, S. Patel, J. Liu, P. Wang, C.S.E. Lai, M. Gou, Y. Xu, K. Zhang, S. Chen, Direct 3D bioprinting of prevascularized tissue constructs with complex microarchitecture, Biomaterials 124 (2017) 106-115, doi:10.1016/ J.BIOMATERIALS.2017.01.042.

[15] K.T. Morin, R.T. Tranquillo, In vitro models of angiogenesis and vasculogenesis in fibrin gel, Exp. Cell Res. 319 (2013) 2409-2417, doi:10.1016/j.yexcr.2013.06. 006.

[16] K.T. Morin, A.O. Smith, G.E. Davis, R.T. Tranquillo, Aligned human microvessels formed in 3D fibrin gel by constraint of gel contraction, Microvasc. Res. 90 (2013) 12-22, doi:10.1016/j.mvr.2013.07.010.

[17] K.S. Thomson, F.S. Korte, C.M. Giachelli, B.D. Ratner, M. Regnier, M. Scatena, Prevascularized microtemplated fibrin scaffolds for cardiac tissue engineering applications, Tissue Eng. Part A. 19 (2013) 967-977, doi:10.1089/ten.tea.2012. 0286.

[18] S. Raghavan, C.M. Nelson, J.D. Baranski, E. Lim, C.S. Chen, Geometrically controlled endothelial tubulogenesis in micropatterned gels, Tissue Eng. Part A. 16 (2010) 2255-2263, doi:10.1089/ten.TEA.2009.0584.

[19] C. Deroanne, C.M. Lapiere, B.V. Nusgens, In vitro tubulogenesis of endothelial cells by relaxation of the coupling extracellular matrix-cytoskeleton, Cardiovasc. Res. 49 (2001) 647-658, doi:10.1016/S0008-6363(00)00233-9.

[20] J.P.P. Waters, M.S.S. Kluger, M. Graham, W.G.G. Chang, J.R.R. Bradley, J.S.S. Pober, J.S.S. Pober, In vitro self-assembly of human pericyte-supported endothelial microvessels in three-dimensional coculture: a simple model for interrogating endothelial-pericyte interactions, J. Vasc. Res. 50 (2013) 324-331, doi:10.1159/ 000353303.

[21] H.W. Kang, S.J. Lee, I.K. Ko, C. Kengla, J.J. Yoo, A. Atala, A 3D bioprinting system to produce human-scale tissue constructs with structural integrity, Nat Biotechnol. 34 (2016) 312-319, doi:10.1038/nbt.3413.

[22] E. Alsberg, H.J. Kong, Y. Hirano, M.K. Smith, A. Albeiruti, D.J. Mooney, Regulating bone formation via controlled scaffold degradation, J. Dent. Res. 82 (2003) 903-908, doi:10.1177/154405910308201111.

[23] O. Jeon, C. Powell, S.M. Ahmed, E. Alsberg, Biodegradable, photocrosslinked alginate hydrogels with independently tailorable physical properties and cell adhesivity, Tissue Eng. Part A. 16 (2010) 2915-2925, doi:10.1089/ten.tea.2010. 0096. 
[24] H. Shin, B.D. Olsen, A. Khademhosseini, The mechanical properties and cytotoxicity of cell-laden double-network hydrogels based on photocrosslinkable gelatin and gellan gum biomacromolecules, Biomaterials 33 (2012) 3143-3152, doi:10.1016/J.BIOMATERIALS.2011.12.050.

[25] B.H. Lee, H. Shirahama, N.J. Cho, L.P. Tan, Efficient and controllable synthesis of highly substituted gelatin methacrylamide for mechanically stiff hydrogels, RSC Adv. 5 (2015) 106094-106097, doi:10.1039/C5RA22028A.

[26] F.E. Freeman, D.J. Kelly, Tuning alginate bioink stiffness and composition for controlled growth factor delivery and to spatially direct MSC Fate within bioprinted tissues, Sci. Rep. 7 (2017) 1-12, doi:10.1038/s41598-017-17286-1.

[27] T. Vinardell, S.D. Thorpe, C.T. Buckley, D.J. Kelly, Chondrogenesis and integration of mesenchymal stem cells within an in vitro cartilage defect repair model, Ann. Biomed. Eng. 37 (2009) 2556-2565, doi:10.1007/ s10439-009-9791-1.

[28] G. Cunniffe, P. Díaz-Payno, J. Ramey, O. Mahon, A. Dunne, E. Thompson, F. O'Brien, D. Kelly, Growth plate extracellular matrix-derived scaffolds for large bone defect healing, Eur. Cells Mater. 33 (2017) 130-142, doi:10.22203/ eCM.v033a10.

[29] N.Y. Ignat'eva, N.A. Danilov, S.V. Averkiev, M.V. Obrezkova, V.V. Lunin, E.N. Sobol, Determination of hydroxyproline in tissues and the evaluation of the collagen content of the tissues, J. Anal. Chem. 62 (2007) 51-57, doi:10. 1134/S106193480701011X

[30] E. Zudaire, L. Gambardella, C. Kurcz, S. Vermeren, A computational tool for quantitative analysis of vascular networks, PLoS ONE 6 (2011) e27385, doi:10. 1371/journal.pone.0027385.

[31] K.F. Eichholz, S. Von Euw, R. Burdis, D.J. Kelly, D.A. Hoey, Development of a new bone-mimetic surface treatment platform: nanoneedle hydroxyapatite (nnHA) coating, Adv. Healthc. Mater. (2020) 2001102, doi:10.1002/adhm. 202001102.

[32] F. Liu, E. Ferreira, R.M. Porter, V. Glatt, M. Schinhan, Z. Shen, M.A. Randolph, C.A. Kirker-Head, C. Wehling, M.S. Vrahas, C.H. Evans, J.W. Wells, Rapid and reliable healing of critical size bone defects with genetically modified sheep muscle, Eur. Cell. Mater. 30 (2015) 118-130 discussion 130-1., doi:10.22203/ eCM.v030a09.

[33] R.E. De La Vega, C.L. De Padilla, M. Trujillo, N. Quirk, R.M. Porter, C.H. Evans, E. Ferreira, Contribution of Implanted, genetically modified muscle progenitor cells expressing BMP-2 to new bone formation in a rat osseous defect, Mol. Ther. 26 (2018) 208-218, doi:10.1016/J.YMTHE.2017.10.001.

[34] A.C. Daly, S.E. Critchley, E.M. Rensock, D.J. Kelly, A comparison of different bioinks for 3D bioprinting of fibrocartilage and hyaline cartilage, Biofabrication 8 (2016) 1-25, doi:10.1088/1758-5090/8/4/045002

[35] J. Malda, J. Visser, F.P. Melchels, T. Jüngst, W.E. Hennink, W.J.A. Dhert, J. Groll, D.W. Hutmacher, 25th anniversary article: engineering hydrogels for biofabrication, Adv. Mater. 25 (2013) 5011-5028, doi:10.1002/adma.201302042.

[36] A.C. Daly, S.E. Critchley, E.M. Rencsok, D.J. Kelly, 3D bioprinting of spatially graded $\mathrm{PCL} /$ hydrogel constructs for cartilage tissue engineering, TISSUE Eng. PART A. 21 (2015) S187-S188 http://apps.webofknowledge. com/full_record.do?product=UA\&search_mode=GeneralSearch\&qid=1\&SID= Q1WCvfEsdgLGMA6fmpa\&page=2\&doc=17. (accessed March 23, 2016)

[37] T. Billiet, E. Gevaert, T. De Schryver, M. Cornelissen, P. Dubruel, The 3D printing of gelatin methacrylamide cell-laden tissue-engineered constructs with high cell viability, Biomaterials 35 (2014) 49-62, doi:10.1016/j.biomaterials.2013.09. 078.

[38] K. Nair, M. Gandhi, S. Khalil, K.C. Yan, M. Marcolongo, K. Barbee, W. Sun, Characterization of cell viability during bioprinting processes, Biotechnol. J. 4 (2009) 1168-1177, doi:10.1002/biot.200900004.

[39] G. Bergers, S. Song, The role of pericytes in blood-vessel formation and maintenance, Neuro. Oncol. 7 (2005) 452-464, doi:10.1215/S1152851705000232.

[40] X. Chen, A.S. Aledia, C.M. Ghajar, C.K. Griffith, A.J. Putnam, C.C.W.W. Hughes, S.C. George, Prevascularization of a fibrin-based tissue construct accelerates the formation of functional anastomosis with host vasculature, Tissue Eng. Part A. 15 (2009) 1363-1371, doi:10.1089/ten.tea.2008.0314

[41] N. Koike, D. Fukumura, O. Gralla, P. Au, J.S. Schechner, R.K. Jain, Tissue engineering: creation of long-lasting blood vessels, Nature 428 (2004) 138-139, doi:10.1038/428138a.

[42] S. Levenberg, J. Rouwkema, M. Macdonald, E.S. Garfein, D.S. Kohane, D.C. Darland, R. Marini, C.A. van Blitterswijk, R.C. Mulligan, P.A. D’Amore, R. Langer, P.A. D 'amore, R. Langer, Engineering vascularized skeletal muscle tissue, Nat. Biotechnol. 23 (2005) 879-884, doi:10.1038/nbt1109.

[43] A.I. Caplan, All MSCs are pericytes? Cell Stem Cell 3 (2008) 229-230, doi:10. 1016/j.stem.2008.08.008.

[44] C. Gallina, V. Turinetto, C. Giachino, A new paradigm in cardiac regeneration: the mesenchymal stem cell secretome, Stem Cells Int. 2015 (2015) 765846, doi: $10.1155 / 2015 / 765846$.

[45] K.J. Bayless, H.I. Kwak, S.C. Su, Investigating endothelial invasion and sprouting behavior in three-dimensional collagen matrices, Nat. Protoc. 4 (2009) 18881898, doi:10.1038/nprot.2009.221

[46] L. Liu, B.D. Ratner, E.H. Sage, S. Jiang, Endothelial cell migration on surfacedensity gradients of fibronectin, VEGF, or both proteins, Langmuir 23 (2007) 11168-11173, doi:10.1021/la701435x.

[47] V. Speirs, Matrix metalloproteinases and angiogenesis, Breast Cancer Res 2 (2000) 267-285, doi:10.1186/bcr-2000-66702.

[48] K.B. Fonseca, D.B. Gomes, K. Lee, S.G. Santos, A. Sousa, E.A. Silva, D.J. Mooney, P.L. Granja, C.C. Barrias, Injectable MMP-sensitive alginate hydrogels as hMSC delivery systems, Biomacromolecules 15 (2014) 380-390, doi:10.1021/ bm4016495.
[49] B. Klotz, K. Lim, Y. Chang, B. Soliman, I. Pennings, F. Melchels, T. Woodfield, A. Rosenberg, J. Malda, D. Gawlitta, Engineering of a complex bone tissue model with endothelialised channels and capillary-like networks, Eur. Cells Mater. 35 (2018) 335-349, doi:10.22203/eCM.v035a23.

[50] A.L. Sieminski, R.P. Hebbel, K.J. Gooch, The relative magnitudes of endothelial force generation and matrix stiffness modulate capillary morphogenesis in vitro, Exp. Cell Res. 297 (2004) 574-584, doi:10.1016/j.yexcr.2004.03.035.

[51] E. Kniazeva, A.J. Putnam, Endothelial cell traction and ECM density influence both capillary morphogenesis and maintenance in 3-D, Am. J. Physiol. - Cell Physiol. 297 (2009) 179-187, doi:10.1152/ajpcell.00018.2009.

[52] F. Bordeleau, B.N. Mason, E.M. Lollis, M. Mazzola, M.R. Zanotelli, S. Somasegar, J.P. Califano, C. Montague, D.J. LaValley, J. Huynh, N. Mencia-Trinchant, Y.L. Negrón Abril, D.C. Hassane, L.J. Bonassar, J.T. Butcher, R.S. Weiss, C.A. ReinhartKing, Matrix stiffening promotes a tumor vasculature phenotype, Proc. Natl. Acad. Sci. 114 (2017) 492-497, doi:10.1073/pnas.1613855114.

[53] A. Lee, A.R. Hudson, D.J. Shiwarski, J.W. Tashman, T.J. Hinton, S. Yerneni, J.M. Bliley, P.G. Campbell, A.W. Feinberg, 3D bioprinting of collagen to rebuild components of the human heart, Science (80) 365 (2019) 482-487, doi:10.1126/SCIENCE.AAV9051.

[54] T.J. Hinton, Q. Jallerat, R.N. Palchesko, J.H. Park, M.S. Grodzicki, H.J. Shue, M.H. Ramadan, A.R. Hudson, A.W. Feinberg, Three-dimensional printing of complex biological structures by freeform reversible embedding of suspended hydr(1), Sci Adv 1 (2015) 1-10, doi:10.1126/sciadv.1500758.

[55] G. Bergers, S. Song, The role of pericytes in blood-vessel formation and maintenance, Neuro. Oncol. 7 (2005) 452-464, doi:10.1215/S1152851705000232.

[56] A.I. Caplan, New MSC: mSCs as pericytes are Sentinels and gatekeepers, J. Orthop. Res. 35 (2017) 1151-1159, doi:10.1002/jor.23560.

[57] R. Kuroda, K. Ishida, T. Matsumoto, T. Akisue, H. Fujioka, K. Mizuno, H. Ohgushi, S. Wakitani, M. Kurosaka, Treatment of a full-thickness articular cartilage defect in the femoral condyle of an athlete with autologous bone-marrow stromal cells, Osteoarthr. Cartil. 15 (2007) 226-231, doi:10.1016/j.joca.2006.08.008.

[58] E.M. Horwitz, P.L. Gordon, W.K.K. Koo, J.C. Marx, M.D. Neel, R.Y. McNall, L. Muul, T. Hofmann, Isolated allogeneic bone marrow-derived mesenchymal cells engraft and stimulate growth in children with osteogenesis imperfecta: implications for cell therapy of bone, Proc. Natl. Acad. Sci. U. S. A. 99 (2002) 8932-8937, doi:10.1073/pnas.132252399.

[59] B. Fang, Y.P. Song, L.M. Liao, Q. Han, R.C. Zhao, Treatment of severe therapyresistant acute graft-versus-host disease with human adipose tissue-derived mesenchymal stem cells [3], Bone Marrow Transplant. 38 (2006) 389-390, doi:10.1038/sj.bmt.1705457.

[60] K.H. Wu, C.K. Chan, C. Tsai, Y.H. Chang, M. Sieber, T.H. Chiu, M. Ho, C.T. Peng, H.P. Wu, J.L. Huang, Effective treatment of severe steroid-resistant acute graftversus-host disease with umbilical cord-derived mesenchymal stem cells, Transplantation 91 (2011) 1412-1416, doi:10.1097/TP.0b013e31821aba18.

[61] M. Studeny, F.C. Marini, R.E. Champlin, C. Zompetta, I.J. Fidler, M. Andreeff, Bone marrow-derived mesenchymal stem cells as vehicles for interferon- $\beta$ delivery into tumors, Cancer Res. 62 (2002)

[62] M.R. Loebinger, A. Eddaoudi, D. Davies, S.M. Janes, Mesenchymal stem cell delivery of TRAIL can eliminate metastatic cancer, Cancer Res. 69 (2009) 41344142, doi:10.1158/0008-5472.CAN-08-4698.

[63] J.M. Bourget, O. Kérourédan, M. Medina, M. Rémy, N.B. Thébaud, R. Bareille, O. Chassande, J. Amédeé, S. Catros, R. Devillard, Patterning of endothelial cells and mesenchymal stem cells by laser-assisted bioprinting to study cell migration, Biomed Res. Int. 2016 (2016), doi:10.1155/2016/3569843.

[64] O. Kérourédan, D. Hakobyan, M. Rémy, S. Ziane, N. Dusserre, J.C. Fricain, S. Delmond, N.B. Thébaud, R. Devillard, In situ prevascularization designed by laserassisted bioprinting: effect on bone regeneration, Biofabrication. 11 (2019) 045002, doi:10.1088/1758-5090/ab2620.

[65] M. Grellier, N. Ferreira-Tojais, C. Bourget, R. Bareillke, F. Guillemot, J. Amédée, Role of vascular endothelial growth factor in the communication between human osteoprogenitors and endothelial cells, J. Cell. Biochem. 106 (2009) 390398, doi:10.1002/jcb.22018.

[66] M. Grellier, P.L. Granja, J.C. Fricain, S.J. Bidarra, M. Renard, R. Bareille, C. Bourget, J. Amédée, M.A. Barbosa, The effect of the co-immobilization of human osteoprogenitors and endothelial cells within alginate microspheres on mineralization in a bone defect, Biomaterials 30 (2009) 3271-3278, doi:10.1016/j. biomaterials.2009.02.033.

[67] B. Guillotin, R. Bareille, C. Bourget, L. Bordenave, J. Amédée, Interaction between human umbilical vein endothelial cells and human osteoprogenitors triggers pleiotropic effect that may support osteoblastic function, Bone 42 (2008) 1080-1091, doi:10.1016/j.bone.2008.01.025.

[68] B. Guillotin, C. Bourget, M. Remy-Zolgadri, R. Bareille, P. Fernandez, V. Conrad, J. Amédée-Vilamitjana, Human primary endothelial cells stimulate human osteoprogenitor cell differentiation, Cell. Physiol. Biochem. 14 (2004) 325-332, doi:10.1159/000080342.

[69] F. Villars, B. Guillotin, T. Amédée, S. Dutoya, L. Bordenave, R. Bareille, J. Amédée, Effect of HUVEC on human osteoprogenitor cell differentiation needs heterotypic gap junction communication, Am. J. Physiol. - Cell Physiol. 282 (2002), doi:10.1152/ajpcell.00310.2001.

[70] J.M. Capla, D.J. Ceradini, O.M. Tepper, M.J. Callaghan, K.A. Bhatt, R.D. Galiano, J.P. Levine, G.C. Gurtner, Skin graft vascularization involves precisely regulated regression and replacement of endothelial cells through both angiogenesis and vasculogenesis, Plast. Reconstr. Surg. 117 (2006) 836-844, doi:10.1097/01.prs. 0000201459.91559.7f.

[71] M.W. Laschke, M. Rücker, G. Jensen, C. Carvalho, R. Mülhaupt, N.C. Gellrich, M.D. Menger, Improvement of vascularization of PLGA scaffolds by inoscula- 
tion of in situ-preformed functional blood vessels with the host microvasculature, Ann. Surg. 248 (2008) 939-948, doi:10.1097/SLA.0b013e31818fa52f.

[72] R.E. Unger, A. Sartoris, K. Peters, A. Motta, C. Migliaresi, M. Kunkel, U. Bulnheim, J. Rychly, C.J. Kirkpatrick, Tissue-like self-assembly in cocultures of endothelial cells and osteoblasts and the formation of microcapillary-like structures on three-dimensional porous biomaterials, Biomaterials 28 (2007) 3965-3976, doi:10.1016/J.BIOMATERIALS.2007.05.032.

[73] A. Freiman, Y. Shandalov, D. Rozenfeld, E. Shor, S. Segal, D. Ben-David, S. Meretzki, D. Egozi, S. Levenberg, Adipose-derived endothelial and mesenchymal stem cells enhance vascular network formation on three-dimensional constructs in vitro, Stem Cell Res. Ther. 7 (2016) 5, doi:10.1186/s13287-015-0251-6.

[74] J.M. Melero-Martin, Z.A. Khan, A. Picard, X. Wu, S. Paruchuri, J. Bischoff, In vivo vasculogenic potential of human blood-derived endothelial progenitor cells, Blood 109 (2007) 4761-4768, doi:10.1182/blood-2006-12-062471.

[75] J.M. Melero-Martin, M.E. De Obaldia, S.Y. Kang, Z.A. Khan, L. Yuan, P. Oettgen, J. Bischoff, Engineering robust and functional vascular networks in vivo with human adult and cord blood-derived progenitor cells, Circ. Res. 103 (2008) 194-202, doi:10.1161/CIRCRESAHA.108.178590.

[76] D.O. Traktuev, D.N. Prater, S. Merfeld-Clauss, A.R. Sanjeevaiah, M.R. Saadatzadeh, M. Murphy, B.H. Johnstone, D.A. Ingram, K.L. March, Robust functional vascular network formation in vivo by cooperation of adipose progenitor and endothelial cells, Circ. Res. 104 (2009) 1410-1420, doi:10.1161/ CIRCRESAHA.108.190926.

[77] P. Au, L.M. Daheron, D.G. Duda, K.S. Cohen, J.A. Tyrrell, R.M. Lanning, D. Fukumura, D.T. Scadden, R.K. Jain, Differential in vivo potential of endothelial progenitor cells from human umbilical cord blood and adult peripheral blood to form functional long-lasting vessels, Blood 111 (2008) 1302-1305, doi:10.1182/ blood-2007-06-094318.

[78] X. Chen, A.S. Aledia, C.M. Ghajar, C.K. Griffith, A.J. Putnam, C.C.W. Hughes, S.C. George, Prevascularization of a fibrin-based tissue construct accelerates the formation of functional anastomosis with host vasculature, Tissue Eng. Part A. 15 (2009) 1363-1371, doi:10.1089/ten.tea.2008.0314.

[79] F.E. Freeman, A.B. Allen, H.Y. Stevens, R.E. Guldberg, L.M. McNamara, Effects of in vitro endochondral priming and pre-vascularisation of human MSC cellular aggregates in vivo, Stem Cell Res. Ther. 6 (2015) 218, doi:10.1186/ s13287-015-0210-2.

[80] G.D.G. Barabaschi, V. Manoharan, Q. Li, L.E. Bertassoni, Engineering prevascularized scaffolds for bone regeneration, in: Adv. Exp. Med. Biol., Springer, Cham, 2015, pp. 79-94, doi:10.1007/978-3-319-22345-2_5.

[81] B.M. Roux, B. Akar, W. Zhou, K. Stojkova, B. Barrera, J. Brankov, E.M. Brey, Preformed vascular networks survive and enhance vascularization in critical sized cranial defects, Tissue Eng. Part A. 24 (2018) 1603-1615, doi:10.1089/ten.TEA. 2017.0493.

[82] M. Yaghoobi, S. Hashemi-Najafabadi, M. Soleimani, E. Vasheghani-Farahani, S.M. Mousavi, Osteogenic differentiation and mineralization on compact multilayer nHA-PCL electrospun scaffolds in a perfusion bioreactor, Iran. J. Biotechnol. 14 (2016) 41-49, doi:10.15171/ijb.1382.

[83] D.B. Kolesky, R.L. Truby, A.S. Gladman, T.A. Busbee, K.A. Homan, J.A. Lewis, 3D bioprinting of vascularized, heterogeneous cell-laden tissue constructs, Adv. Mater. 26 (2014) 3124-3130, doi:10.1002/adma.201305506.
[84] D.B. Kolesky, K.A. Homan, M.A. Skylar-Scott, J.A. Lewis, Three-dimensional bioprinting of thick vascularized tissues, Proc. Natl. Acad. Sci. 113 (2016) 31793184, doi:10.1073/pnas.1521342113.

[85] J. Hammer, L.H. Han, X. Tong, F. Yang, A facile method to fabricate hydrogels with microchannel-like porosity for tissue engineering, Tissue Eng. Part C. Methods. 20 (2014) 169-176, doi:10.1089/ten.TEC.2013.0176.

[86] L.E. Bertassoni, J.C. Cardoso, V. Manoharan, A.L. Cristino, N.S. Bhise, W.A. Araujo, P. Zorlutuna, N.E. Vrana, A.M. Ghaemmaghami, M.R. Dokmeci, A. Khademhosseini, Direct-write bioprinting of cell-laden methacrylated gelatin hydrogels, Biofabrication 6 (2014) 024105, doi:10.1088/1758-5082/6/2/ 024105.

[87] O. Kérourédan, J.M. Bourget, M. Rémy, S. Crauste-Manciet, J. Kalisky, S. Catros, N.B. Thébaud, R. Devillard, Micropatterning of endothelial cells to create a capillary-like network with defined architecture by laser-assisted bioprinting, J. Mater. Sci. Mater. Med. 30 (2019), doi:10.1007/s10856-019-6230-1.

[88] F. Kawecki, W.P. Clafshenkel, F.A. Auger, J.M. Bourget, J. Fradette, R. Devillard, Self-assembled human osseous cell sheets as living biopapers for the laser-assisted bioprinting of human endothelial cells, Biofabrication 10 (2018), doi:10.1088/1758-5090/aabd5b.

[89] N. Brandenberg, M.P. Lutolf, Situ patterning of microfluidic networks in 3D Cell-Laden hydrogels, Adv. Mater. 28 (2016) 7450-7456, doi:10.1002/adma. 201601099

[90] C.K. Arakawa, B.A. Badeau, Y. Zheng, C.A. DeForest, Multicellular vascularized engineered tissues through user-programmable biomaterial photodegradation, Adv. Mater. 29 (2017) 1703156, doi:10.1002/adma.201703156.

[91] K.S. Lim, R. Levato, P.F. Costa, M.D. Castilho, C.R. Alcala-Orozco, K.M.A. van Dorenmalen, F.P.W. Melchels, D. Gawlitta, G.J. Hooper, J. Malda, T.B.F. Woodfield, Bio-resin for high resolution lithography-based biofabrication of complex cell-laden constructs, Biofabrication 10 (2018) 034101, doi:10.1088/1758-5090/ aac00c.

[92] O. Ilina, G.J. Bakker, A. Vasaturo, R.M. Hofmann, P. Friedl, Two-photon lasergenerated microtracks in 3D collagen lattices: principles of MMP-dependent and -independent collective cancer cell invasion, Phys. Biol. 8 (2011) 015010, doi:10.1088/1478-3975/8/1/015010.

[93] K.A. Heintz, M.E. Bregenzer, J.L. Mantle, K.H. Lee, J.L. West, J.H. Slater, Fabrication of 3D biomimetic microfluidic networks in hydrogels, Adv. Healthc. Mater. 5 (2016) 2153-2160, doi:10.1002/adhm.201600351.

[94] M.B. Applegate, J. Coburn, B.P. Partlow, JE. Moreau, J.P. Mondia, B. Marelli, D.L. Kaplan, F.G. Omenetto, Laser-based three-dimensional multiscale micropatterning of biocompatible hydrogels for customized tissue engineering scaffolds, Proc. Natl. Acad. Sci. U. S. A. 112 (2015) 12052-12057, doi:10.1073/ pnas.1509405112.

[95] O. Kérourédan, D. Hakobyan, M. Rémy, S. Ziane, N. Dusserre, J.C. Fricain, S. Delmond, N.B. Thébaud, R. Devillard, In situ prevascularization designed by laserassisted bioprinting: effect on bone regeneration, Biofabrication 11 (2019) 045002, doi:10.1088/1758-5090/ab2620. 